\title{
Bioactive Cembrane Derivatives from the Indian Ocean Soft Coral, Sinularia kavarattiensis
}

Katja-Emilia Lillsunde ${ }^{1}$, Carmen Festa ${ }^{2}$, Harshada Adel ${ }^{3}$, Simona De Marino ${ }^{2}$, Valter Lombardi ${ }^{4}$, Supriya Tilvi ${ }^{3}$, Dorota A. Nawrot ${ }^{1}$, Angela Zampella ${ }^{2}$, Lisette D'Souza $^{3}$, Maria Valeria D'Auria ${ }^{2}$ and Päivi Tammela ${ }^{1, *}$

1 Centre for Drug Research, Division of Pharmaceutical Biosciences, Faculty of Pharmacy, P.O. Box 56, University of Helsinki, Helsinki FI-00014, Finland;

E-Mails: katja-emilia.lillsunde@helsinki.fi (K.-E.L.); dorota.nawrot@helsinki.fi (D.A.N.)

2 Department of Pharmacy, University of Naples Federico II (USNF), Naples I-80131, Italy; E-Mails: carmen.festa@unina.it (C.F.); sidemari@unina.it (S.D.M.); azampell@unina.it (A.Z.); madauria@unina.it (M.V.D.)

3 CSIR-National Institute of Oceanography, Dona Paula, Goa 403004, India; E-Mails: hadel@nio.org (H.A.); supriyatilvi@nio.org (S.T.); lisette@nio.org (L.D.)

4 EuroEspes Biotechnology, Department of Cellular Immunology, Bergondo 15165, A Coruña, Spain; E-Mail: biotecnologia@ebiotec.com

* Author to whom correspondence should be addressed; E-Mail: paivi.tammela@helsinki.fi; Tel.: +358-2941-59628; Fax: +358-2941-59138.

Received: 1 April 2014; in revised form: 5 June 2014 / Accepted: 17 June 2014 /

Published: 3 July 2014

Abstract: Marine organisms and their metabolites represent a unique source of potential pharmaceutical substances. In this study, we examined marine-derived substances for their bioactive properties in a cell-based Chikungunya virus (CHIKV) replicon model and for in vitro anti-inflammatory activity. In the screening of a marine sample library, crude extracts from the Indian soft coral, Sinularia kavarattiensis, showed promising activity against the CHIKV replicon. Bioassay-guided chemical fractionation of S. kavarattiensis resulted in the isolation of six known norcembranoids (1-6) and one new compound, named kavaranolide (7). The structures were elucidated on the basis of NMR and MS spectroscopic data. Compounds 1-3 and 5-7 were evaluated for their replicon-inhibiting potential in the CHIKV model by using a luminescence-based detection technique and live cell imaging. Compounds $\mathbf{1}$ and $\mathbf{2}$ showed moderate inhibition of the CHIKV replicon, but imaging studies also revealed cytotoxic properties. Moreover, the effects of the isolated 
compounds on primary microglial cells, an experimental model for neuroinflammation, were evaluated. Compound 2 was shown to modulate the immune response in microglial cells and to possess potential anti-inflammatory properties by dose-dependently reducing the release of pro- and anti-inflammatory cytokines.

Keywords: Sinularia kavarattiensis; soft coral; norcembranoid; NMR spectroscopy; Chikungunya; replicon cell line; live cell imaging; neuroinflammation

\section{Introduction}

Chikungunya virus (CHIKV) is an alphavirus transmitted by Aedes mosquitoes and the cause of Chikungunya fever, a disease characterized by acute high fever, polyarthralgia, myalgia, nausea, headache and skin symptoms [1-3]. In addition to acute phase symptoms, CHIKV infection is often associated with chronic rheumatic manifestations that are relapsing and incapacitating [4,5]. The rheumatic symptoms can persist from months to years after the initial virus infection.

A new lineage of CHIKV emerged in 2004 as a result of a single mutation in the viral genome, which enabled the adaptation of the virus to the Aedes albopictus mosquito vector, a common vector of arthropod-borne diseases [6,7]. This mutation permitted the massive spread of the virus to many countries in the Indian Ocean region in the epidemics that escalated in 2005 [8]. As a consequence of vector adaptation and the resulting Chikungunya epidemic, local transmission of the virus has lately been reported not only in tropical, but also in temperate regions, such as Italy and south-eastern France [9-11]. There are currently neither vaccines nor specific therapies against CHIKV, and hence, infections can only be avoided by preventing exposure to mosquitoes in affected regions. The current treatment is symptomatic and mainly includes analgesics, anti-inflammatory drugs and corticosteroids [3].

The CHIKV genome is a single-stranded positive-sense RNA, which encodes for structural and non-structural proteins [12]. The genetic material is protected by a nucleocapsid, and the virion enters its host cell via receptor-mediated endocytosis. The drug discovery approaches applied to the treatment and prevention of CHIKV infection include entry inhibition, interference with viral protein translation, protein replication inhibition and modulation of the host immune response [13]. The replicon cell line used in our study expresses CHIKV non-structural proteins and can be used to identify potential CHIKV replication inhibitors. The replicon cell line enables safe and efficient screening that can be performed in a biosafety Level 2 laboratory. This is a great advantage compared to studies on infectious CHIKV, which requires handling in biosafety Level 3 facilities.

In the course of the multinational collaborative project, MAREX, a library of extracts originating from marine organisms collected from the Indian Ocean were studied for their potential antiviral properties by using the CHIKV replicon model. The extract of the soft coral, Sinularia kavarattiensis, displayed promising anti-CHIKV activity and was consequently selected for bioassay-guided fractionation. The coral species of the genus, Sinularia, are widespread in coral reefs all over the world and have been reported to contain a variety of compounds with novel chemical structures [14]: sesquiterpenes [15,16], diterpenes [17], in particular cembranoids and norcembranoids, and polyhydroxylated steroids [18], which possess unique structural diversity. These metabolites display potential bioactivities, such as 
antimicrobial [14], anti-inflammatory [19-24], antiviral [25] and cytotoxic activity [26-28]. In the present study, the enriched chloroform extract of $S$. kavarattiensis afforded four known 14-membered macrocyclic norcembranoids, 1-4 (5-epi-sinuleptolide [29], sinuleptolide [30], scabrolide D [31,32] and norcembranoid 4 [33]), all of which lack a C-18 carbon substituent in their structures; one known germacrane-type sesquiterpenoid, 5 (ent-germacra-4(15),5E,10(14)-trien-1 $\beta$-ol) [34], one known $\mathrm{C}_{19}$-norcembranoid diterpene ineleganolide, 6 [35], and the novel norcembranoid, named kavaranolide 7 (Figure 1), possessing a tricyclic carbocycle with the trans-fused six and seven-membered rings.

Figure 1. Compounds (1-7) isolated from the soft coral S. kavarattiensis.

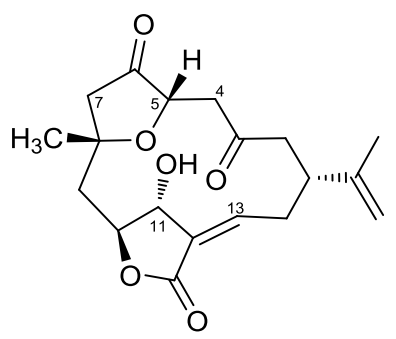

5-epi-sinuleptolide (1)

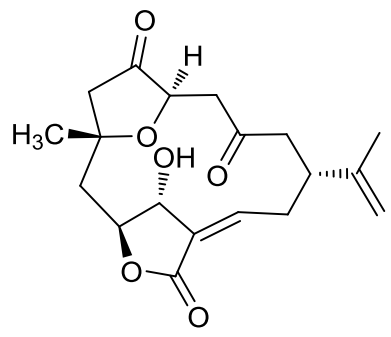

Sinuleptolide (2)

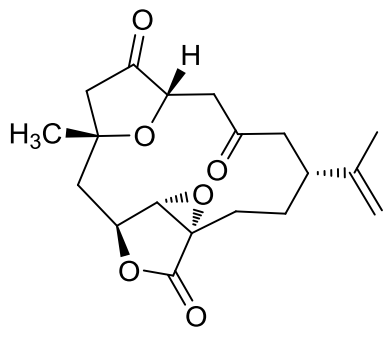

Scabrolide D (3)

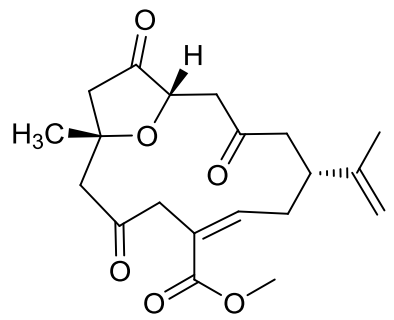

Norcembranoid (4)

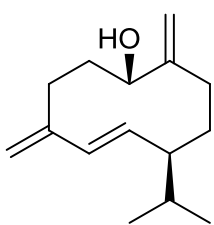

ent-germacra-4(15),5E,10(14)-trien-1 $\beta$-ol (5)

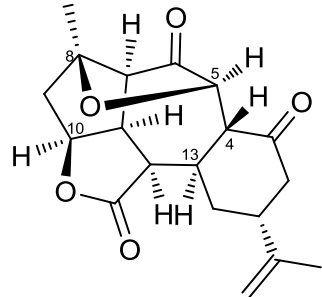

Ineleganolide (6)

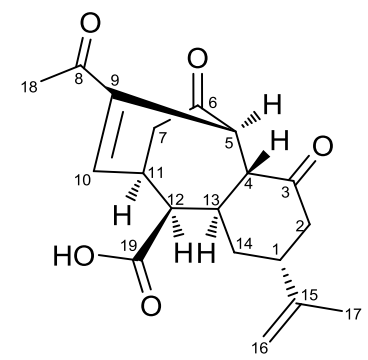

Kavaranolide (7)

S. kavarattiensis was primarily chosen for bioactivity-guided purification based on promising results against the CHIKV replicon. Corals of the genus, Sinularia, are, however, well-known sources of anti-inflammatory agents [19-24]. The isolated compounds were therefore, in addition to anti-CHIKV replicon activity, also studied for potential anti-inflammatory activity in primary microglial cells that serve as a model for neuroinflammation. Microglial cells are the resident immune cells of the central nervous system [36]. In the resting state, microglia are highly dynamic and control the environment by rapidly extending and retracting motile processes. Microglia are closely associated with astrocytes and neurons, particularly at the synapses, and many data indicate that neurotransmission plays a role in regulating the morphology and the function of surveying or resting microglia. The presence of reactive glia has been described in all neurodegenerative diseases, and microglial activation may contribute to the neuropathology observed [37,38]. The inhibition of neuroinflammation has been postulated as a putative target in the treatment of neurodegenerative diseases, and research has focused on the study of the potential neuroprotective effects of anti-inflammatory compounds in experimental models of neurodegeneration occurring in the presence of reactive glia.

The present paper describes bioassay-guided isolation, structure elucidation and antiviral and anti-inflammatory activity studies of the compounds isolated from S. kavarattiensis. 


\section{Results and Discussion}

\subsection{Bioassay-Guided Fractionation of S. kavarattiensis Extract}

In a CHIKV replicon screen of a large marine sample library, we identified potential anti-CHIKV replication activity in the methanol and methanol-chloroform extracts from the marine soft coral, S. kavarattiensis. In primary screening, the extracts showed a 71\% (methanol extract) and $72 \%$ (methanol-chloroform extract) decrease in the Rluc marker levels in the BHK-CHIKV-NCT (baby hamster kidney [BHK] cells expressing a non-cytotoxic [NCT] Chikungunya virus [CHIKV] replicon) cell line at a $100 \mu \mathrm{g} / \mathrm{mL}$ concentration. The crude extracts were tested for cytotoxic activity to rule out the possibility of the reduction in marker levels due to toxicity towards the host cell line. The extracts showed moderate cytotoxicity: the methanol extract caused $15 \%$ cytotoxicity, as measured by the reduction in ATP levels, and the methanol-chloroform extract a 17\% reduction. As a follow up, the activity of the crude extracts was confirmed in dose-response assays. The extracts showed dose-dependent inhibition of the CHIKV replicon in the cell model. These promising results led to the selection of $S$. kavarattiensis for a bioactivity-guided purification study.

The crude methanol extract was fractionated according to the modified Kupchan partitioning procedure [39], and the obtained enriched extracts were studied for replicon inhibition and cytotoxic activity in the BHK-CHIKV-NCT cell line. At a $100 \mu \mathrm{g} / \mathrm{mL}$ concentration, the chloroform- and ethyl acetate-enriched extracts proved to possess inhibitory activity against the CHIKV replicon, causing a $47 \%$ and $65 \%$ decrease of the Rluc marker level, with a cytotoxic effect of $24 \%$ and $20 \%$, respectively. The chloroform-enriched extract (3.2 g) was further fractionated by silica gel MPLC using a solvent gradient system from $\mathrm{CH}_{2} \mathrm{Cl}_{2}$ to $\mathrm{MeOH}$ followed by reverse phase HPLC to afford pure compounds.

\subsection{Chemical Characterization}

Kavaranolide 7 was isolated as a white amorphous solid, and its formula of $\mathrm{C}_{19} \mathrm{H}_{22} \mathrm{O}_{5}$, implying nine degrees of unsaturation, was established by high-resolution ESIMS based on the pseudomolecular ion $[\mathrm{M}-\mathrm{H}]^{-}$at $m / z 329.1381$.

The ${ }^{13} \mathrm{C}$ NMR data confirmed the presence of 19 carbons (Table 1), including three ketone signals at $\delta_{\mathrm{C}} 195.7,207.9$ and 211.3, one acyl signal at $\delta_{\mathrm{C}} 174.1$, one trisubstituted double bond $\left(\delta_{\mathrm{C}} 149.0\right.$, $\mathrm{d}$ and $139.5, \mathrm{~s})$ and one disubstituted double bond $\left(\delta_{\mathrm{C}} 147.2\right.$, s and 111.2, $\left.\mathrm{t}\right)$. The carbonyl and olefinic carbons account for six degrees of unsaturation; hence, the compound is tricyclic. Analysis of the ${ }^{1} \mathrm{H}$ NMR spectrum revealed an isopropenyl group $\left(\delta_{\mathrm{H}} 1.63(3 \mathrm{H}, \mathrm{s}), 4.43,(1 \mathrm{H}\right.$, br s) and $4.75(1 \mathrm{H}, \mathrm{br} \mathrm{s}))$, a deshielded olefin proton at $\delta_{\mathrm{H}} 7.36(1 \mathrm{H}$, br d, $J=7.5 \mathrm{~Hz})$ and a ketone methyl at $\delta_{\mathrm{H}} 2.21(3 \mathrm{H}, \mathrm{s})$.

Careful analysis of the COSY spectrum allowed us to build up a single spin system (Figure 2): H-5, $\mathrm{H}-10$ (by allylic coupling), $\mathrm{H}-11\left(\mathrm{H}_{2}-7\right), \mathrm{H}-12, \mathrm{H}-13$ (H-4), $\mathrm{H}_{2}-14, \mathrm{H}-1$ ( $\mathrm{H}_{2}-16$ and $\mathrm{H}_{3}-17$, by allylic coupling), $\mathrm{H}_{2}-2$. Even if no scalar coupling was observed between $\mathrm{H}-4$ and $\mathrm{H}-5$, the linkage C-4/C-5, as well as the location of two ketone functions at C-3 and C- 6 were easily inferred from HMBC correlations H-5/C-3, C-4, C-6, C-7 and H-4/C-3, C-5, C-6, C-13. The acetyl group was placed at C-9 on the basis of HMBC correlations $\mathrm{H}_{3}-18 / \mathrm{C}-8$, C-9, whereas the long-range correlation, H-12/C-19, allowed the placing of the carboxy group at $\mathrm{C}-12$. These data, together with additional HMBC correlations (Table 1 and Figure 2) defined the planar structure of kavaranolide (7), as depicted in Figure 1. 
Table 1. ${ }^{1} \mathrm{H}$ and ${ }^{13} \mathrm{C}$ NMR data (700 and $175 \mathrm{MHz}$, DMSO- $\left.d_{6}\right)$ of kavaranolide (7).

\begin{tabular}{|c|c|c|c|}
\hline & $\delta_{H}^{a}$ & $\boldsymbol{\delta}_{\mathrm{C}}$ & HMBC \\
\hline 1 & $2.62 \mathrm{~m}$ & 39.9 & \\
\hline $2 \alpha$ & $2.50^{\mathrm{b}}$ & 43.9 & $\mathrm{C} 1, \mathrm{C} 3, \mathrm{C} 15$ \\
\hline $2 \beta$ & $2.36 \mathrm{~m}$ & & C3, C14 \\
\hline 3 & - & 207.9 & \\
\hline 4 & $3.12 \mathrm{~d}(12.6)$ & 50.5 & $\mathrm{C} 3, \mathrm{C} 5, \mathrm{C} 6, \mathrm{C} 13$ \\
\hline 5 & $4.30 \mathrm{br} \mathrm{s}$ & 43.3 & $\mathrm{C} 3, \mathrm{C} 4, \mathrm{C} 6, \mathrm{C} 7, \mathrm{C} 8, \mathrm{C} 9, \mathrm{C} 10, \mathrm{C} 13$ \\
\hline 6 & - & 211.3 & \\
\hline $7 \alpha$ & $2.19^{\mathrm{c}}$ & 39.2 & $\mathrm{C} 6, \mathrm{C} 10, \mathrm{C} 11, \mathrm{C} 12$ \\
\hline $7 \beta$ & $2.24 \mathrm{~m}$ & & $\mathrm{C} 6, \mathrm{C} 12$ \\
\hline 8 & - & 195.7 & \\
\hline 9 & - & 139.5 & \\
\hline 10 & 7.36 br d $(7.5)$ & 149.0 & $\mathrm{C} 5, \mathrm{C} 7, \mathrm{C} 8, \mathrm{C} 11$ \\
\hline 11 & $3.17 \mathrm{~m}$ & 34.7 & \\
\hline 12 & $2.29 \mathrm{dd}(5.2,7.5)$ & 48.8 & $\mathrm{C} 4, \mathrm{C} 10, \mathrm{C} 13, \mathrm{C} 19$ \\
\hline 13 & $1.84 \mathrm{~m}$ & 36.1 & \\
\hline $14 \alpha$ & $1.55 \mathrm{~m}$ & 31.7 & \\
\hline $14 \beta$ & $2.44 \mathrm{~m}$ & & $\mathrm{C} 13, \mathrm{C} 15$ \\
\hline 15 & - & 147.2 & \\
\hline \multirow[t]{2}{*}{16} & 4.75 br s & 111.2 & $\mathrm{C} 1, \mathrm{C} 15, \mathrm{C} 17$ \\
\hline & 4.43 br s & & C1, C17 \\
\hline 17 & $1.63 \mathrm{~s}$ & 21.8 & $\mathrm{C} 1, \mathrm{C} 15, \mathrm{C} 16$ \\
\hline 18 & $2.21 \mathrm{~s}$ & 24.8 & C8, C9 \\
\hline 19 & - & 174.1 & \\
\hline
\end{tabular}

${ }^{\mathrm{a}}$ Coupling constants are in parentheses and given in hertz. ${ }^{1} \mathrm{H}$ and ${ }^{13} \mathrm{C}$ assignments were aided by COSY, HSQC and HMBC experiments; ${ }^{b}$ overlapped with the solvent signal; ${ }^{c}$ overlapped with the other signal.

Figure 2. (a) COSY connectivities (bold bonds) and key HMBC (black arrows) correlations; (b) key NOE (red dashed arrows) correlations for Compound 7.

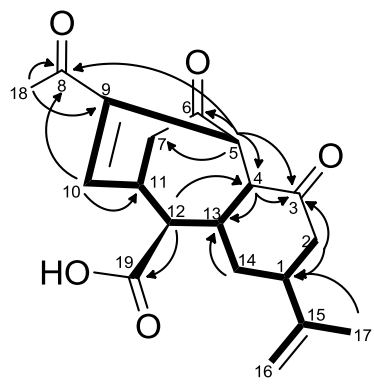

a.

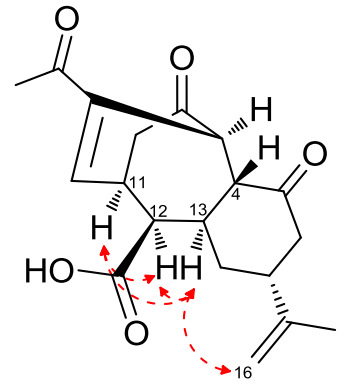

b.

The relative stereochemistry of Compound 7 was deduced from the analysis of the coupling constants and some key dipolar coupling evidenced by the NOESY spectrum (Figure 2).

The NOE correlations between $\mathrm{H}-13 / \mathrm{H}_{2}-16, \mathrm{H}-11$ and $\mathrm{H}-12$ suggested that they are on the same face of the rings. By analogy with ineleganolide [35], which co-occurs in the same specimen and for which the relative configuration has been established by X-ray diffraction analysis, we assigned these signals as $\alpha$ protons. 
The six- and seven-membered rings are trans-fused on the basis of the large value of $J_{\mathrm{H}-4 / \mathrm{H}-13}(12.6 \mathrm{~Hz})$; therefore, $\mathrm{H}-4$ has a $\beta$-orientation. When it comes to the H-5 configuration, no diagnostic dipolar couplings were observed for this proton. The absence of scalar couplings between H-4 and H-5 indicated that they have a dihedral angle of $c a .90^{\circ}$. Force field calculations evidenced that the closure of the bridged structure of kavaranolide and the geometric relationship between $\mathrm{H}-4$ and $\mathrm{H}-5$ were only compatible with an $\alpha$-orientation of the H-5 proton. Therefore, the stereostructure of kavaranolide (7) was determined as depicted in Figure 1. The bridged 6,7,6-ring-fused framework of kavaranolide closely resembles that of ineleganolide (6), also isolated from the extract of $S$. kavarattiensis in the present study, and of horiolide (11), isolated from an Indian Ocean collection of Sinularia sp. [40]. The similar experimental scalar and dipolar coupling patterns observed for ineleganolide (6), horiolide (11) and kavaranolide (7) gave further support to the structural assignment. Furthermore, the observed structural and stereochemical homology between these derivatives suggested a common biosynthetic origin.

Scheme 1. A plausible biosynthetic route to kavaranolide (7).

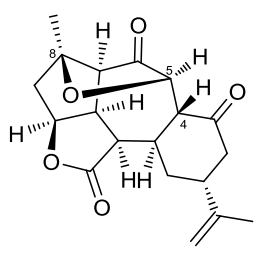

Ineleganolide (6)

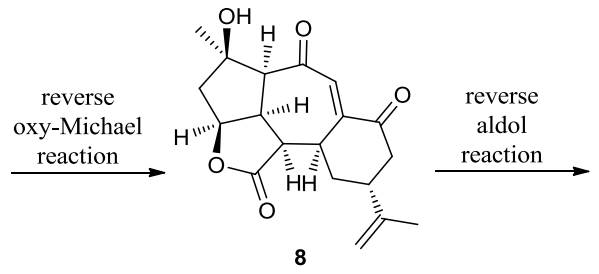

8

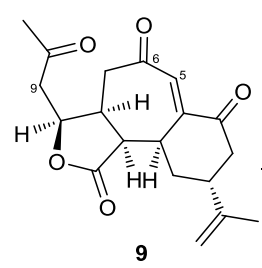

9

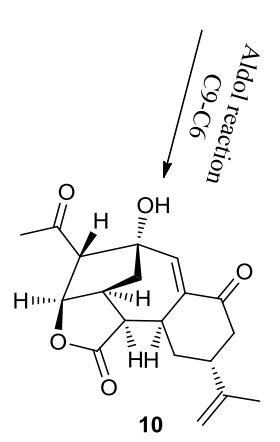

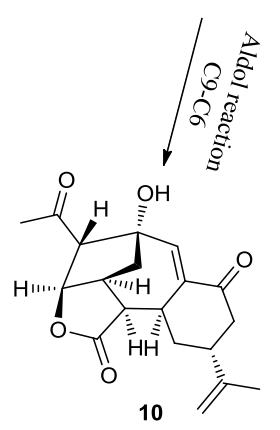

opening the 5-ring lactone Michael reaction $\mathrm{C} 9-\mathrm{C} 5$ dehydration

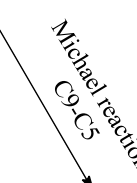

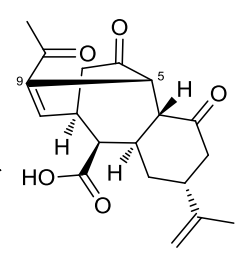

Kavaranolide (7)

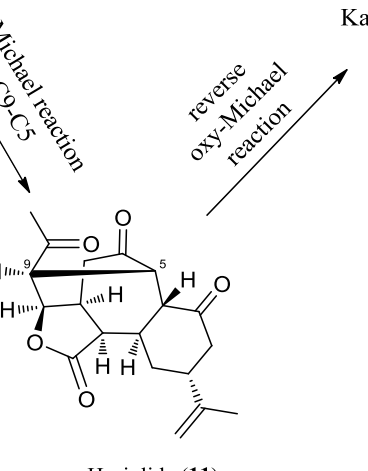

Horiolide (11)

In a recent report, Li et al. [41] proposed biosynthetic pathways that likely lead to polycyclic skeletons of norcembranoids through transannular Michael reactions from norcembranoid macrocyclic precursors. In particular, they speculated that the tricyclic ring system in ineleganolide (6) may originate in vivo from 5-epi-sinuleptolide (1) by two successive Michael reactions, involving the nucleophilic centers at C-4 and C-7 and the electrophilic centers at C-13 and C-11 in 1 [41]. The proposed biosynthetic route to $\mathbf{6}$ from $\mathbf{1}$ was strongly supported by subsequent studies, which demonstrated the in vitro conversion of $\mathbf{1}$ to $\mathbf{6}$, in strong base conditions [42]. Interestingly it turned out that under different experimental conditions, the main product was the novel polycyclic derivative, $\mathbf{1 0}$ (Scheme 1). Its formation from ineleganolide (6) was proposed to take place by a reverse oxy-Michael reaction and two successive aldol reactions. The key trione intermediate, 9, could undergo an aldol reaction leading to the polycyclic derivative, 10, or a Michael reaction leading to horiolide (11). In this context, kavaranolide (7) is likely to be derived in vivo from horiolide (11) by a reverse oxy-Michael reaction (Scheme 1). It is also conceivable that kavaranolide (7) could be derived from trione, 9, by opening of the 5-ring lactone followed by an intramolecular Michael reaction and then dehydration. 
As neither intermediate $\mathbf{9}$ nor intermediate $\mathbf{1 0}$ have been reported as natural compounds, the isolation of kavaranolide (7) gave further support to the proposed biosynthetic route.

\subsection{Inhibition of CHIKV Replicon by Compounds Isolated from S. kavarattiensis}

\subsubsection{Primary Evaluation by Rluc Detection and ATP Quantitation}

The replicon-inhibiting potential of Compounds 1-3 and 5-7 was primarily evaluated in the BHK-CHIKV-NCT cell line by detection of Rluc marker levels as a measure of the inhibition of the CHIKV replicon. Additionally, we evaluated the compounds for cytotoxic activity by ATP quantitation. The compounds, tested at a $100 \mu \mathrm{M}$ concentration, showed the inhibition of the CHIKV replicon ranging from $0.5 \%$ to $63 \%$ (Figure 3 ). The strongest inhibitory effects were observed for Compounds 1 and 2, which both inhibited the CHIKV replicon by more than $60 \%$ compared to the vehicle control. All compounds showed none or only very slight cytotoxicity $(<6 \%)$ in the ATP assay.

Figure 3. Inhibition of the Chikungunya virus (CHIKV) replicon in the primary evaluation of pure Compounds 1-3 and 5-7, determined by the measurement of Rluc marker levels at a $100 \mu \mathrm{M}$ concentration. The percentage of inhibition is based on a comparison of the test compound Rluc levels to the DMSO vehicle control. Inhibition percentages are the averages of the results from three test wells; error bars represent the standard deviation. The positive control, 6-azauridine, inhibited the replicon with an average $\mathrm{IC}_{50}$ value of $2 \mu \mathrm{M}$.

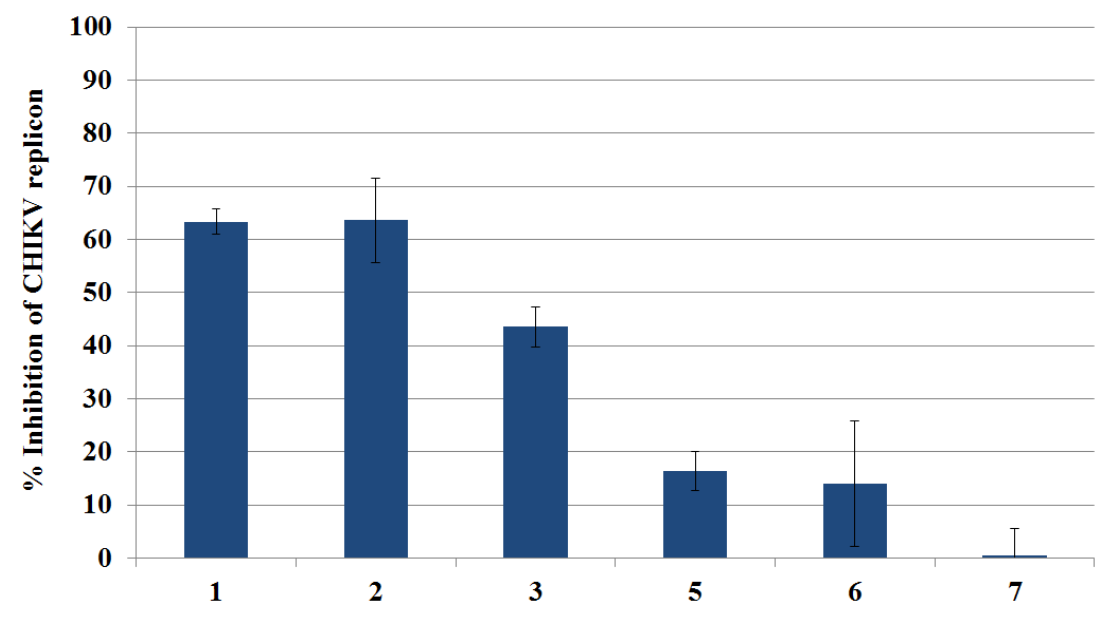

\subsubsection{Live Cell Imaging}

As a follow-up study to the primary assay based on the determination of Rluc expression, cells treated with Compounds 1-3 and 5-7 were monitored for 48 h by live cell imaging in the Cell-IQ ${ }^{\circledR}$ platform. The expression of EGFP marker levels was followed up through fluorescence intensity measurements. This confirmed that Compounds $\mathbf{1}$ and $\mathbf{2}$ cause the strongest decrease in marker protein levels (Figure 4), as observed previously by Rluc detection. Compounds 5, 6 and 7 caused only moderate decreases in the fluorescence intensity. Compound 3, which at a $100 \mu \mathrm{M}$ concentration reduced $R l u c$ marker levels by $44 \%$, turned out to be inactive in the Cell-IQ ${ }^{\circledR}$ experiments at both test concentrations of 50 and $100 \mu \mathrm{M}$. Furthermore, the fluorescence inhibition of 1 was not as prominent as the Rluc inhibition previously observed (Figure 3). 
Furthermore, the Cell-IQ ${ }^{\circledR}$ experiment revealed the cytotoxic effects of Compounds $\mathbf{1}$ and 2, which were not observed by ATP quantitation. At a $100 \mu \mathrm{M}$ concentration, Compounds $\mathbf{1}$ and $\mathbf{2}$ decreased the amount of viable cells (cells classified by the Cell-IQ Analyser ${ }^{\circledR}$ as living or dividing) by $>80 \%$, whereas the effects on the fluorescence intensity levels were not as drastic. The reasons behind these observations remain unclear; however, we hypothesize that the relatively high test concentrations provoking the cytotoxic properties of Compounds $\mathbf{1}$ and $\mathbf{2}$ may lie behind the inconsistencies. In order to further clarify the reasons behind the decrease in cell viability caused by Compounds $\mathbf{1}$ and $\mathbf{2}$, the ATP quantitation and imaging assays were repeated by using the same cell concentration (3000 cells/well) in both experiments. At this concentration, the cell population reaches confluence in 48-72 h, as opposed to the standard concentration of 40,000 cells/well used in the ATP assay, where confluence is reached after overnight incubation. The lower cell concentration applied in live cell imaging facilitates cell classification and the observation of changes in the morphology throughout the experiment. These additional experiments revealed that the cell concentration has a major impact on the resistance of the BHK-CHIKV-NCT cells to the cytotoxic effects of Compounds $\mathbf{1}$ and $\mathbf{2}$. Indeed, when the cell concentration was lowered to 3000 cells/well, Compound 1 reduced the ATP level by $39 \%$ and 2 by $44 \%$ at a $100 \mu \mathrm{M}$ concentration. These results are supported by the fact that cell confluence in general is known to affect cellular responses and, thereby, results in live cell imaging studies [43].

The results from the imaging study also imply that the test concentration may impact the mode of action of Compounds $\mathbf{1}$ and $\mathbf{2}$. At a $50 \mu \mathrm{M}$ concentration of $\mathbf{1}$ and $\mathbf{2}$, the cell number decreased drastically during the $48 \mathrm{~h}$ test, but the remaining cells still appeared viable and bright green in fluorescence microscopy images. At a $100 \mu \mathrm{M}$ concentration, the cell number likewise decreased, and furthermore, the remaining cells were rounded in shape with the reduced expression of EGFP. Based on the results from our study and previous studies on the cytotoxic properties of 1 and 2 [44,45], we hypothesize that at a concentration of $100 \mu \mathrm{M}$, the apoptotic effects are prevailing. At the lower concentration of $50 \mu \mathrm{M}$, the reduced number of viable cells did surprisingly not have a major influence on the overall fluorescence intensity.

The results obtained for the model antiviral compound, 6-azauridine, and the cytotoxic control compound, polymyxin B, in the Rluc detection and ATP assays on BHK-CHIKV-NCT cells corresponded to the results obtained in Cell-IQ ${ }^{\circledR}$. Therefore, the control compounds were used to confirm assay accuracy in Cell-IQ ${ }^{\circledR}$ and to validate the new detection method that the imaging platform offers (see Chapter 3.5.4 for more details). As demonstrated in Figure 4, the inhibition of the CHIKV replicon is mainly achieved at a $100 \mu \mathrm{M}$ concentration of Compounds $\mathbf{1}$ and 2, which clearly also triggers cytotoxicity. The predominance of cytotoxic effects at high concentrations likewise makes further investigation of the dose-response correlation in the CHIKV replicon model challenging and uncertain. For these reasons, the determination of $\mathrm{IC}_{50}$-values for these compounds was not meaningful. The results obtained for Compounds $\mathbf{1}$ and $\mathbf{2}$ by means of live cell imaging and ATP quantitation accentuate the importance of these follow-up studies in the thorough investigation of compound properties in the cell model, before proceeding to more complex and risky experiments, such as studies on infectious viruses. Furthermore, Cell-IQ ${ }^{\circledR}$ enables constant visual monitoring of the cells, as well as their expression of the EGFP marker, whereas Rluc detection and ATP quantitation give only end-point data without the possibility to visualize the results. 
Figure 4. The inhibition of the CHIKV replicon and the cytotoxicity of Compounds 1-3 and 5-7 measured by Cell-IQ ${ }^{\circledR}$ live cell imaging in the BHK-CHIKV-NCT cell line at test concentrations of 50 and $100 \mu \mathrm{M}$. Results are shown together with representative photomicrographs captured after $48 \mathrm{~h}$. The percentage of inhibition and cytotoxicity were calculated by a comparison to the DMSO vehicle control. Values are the averages of two independent assays with three replicates each; error bars represent the standard deviation. Pictomicrographs of cells treated with control compounds $(10 \mu \mathrm{M}$ 6-azauridine and $0.5 \% \mathrm{DMSO}$ ) for $48 \mathrm{~h}$ are shown for comparison. More detailed information on the effects of control compounds in the live cell imaging study can be found in Chapter 3.5.4.

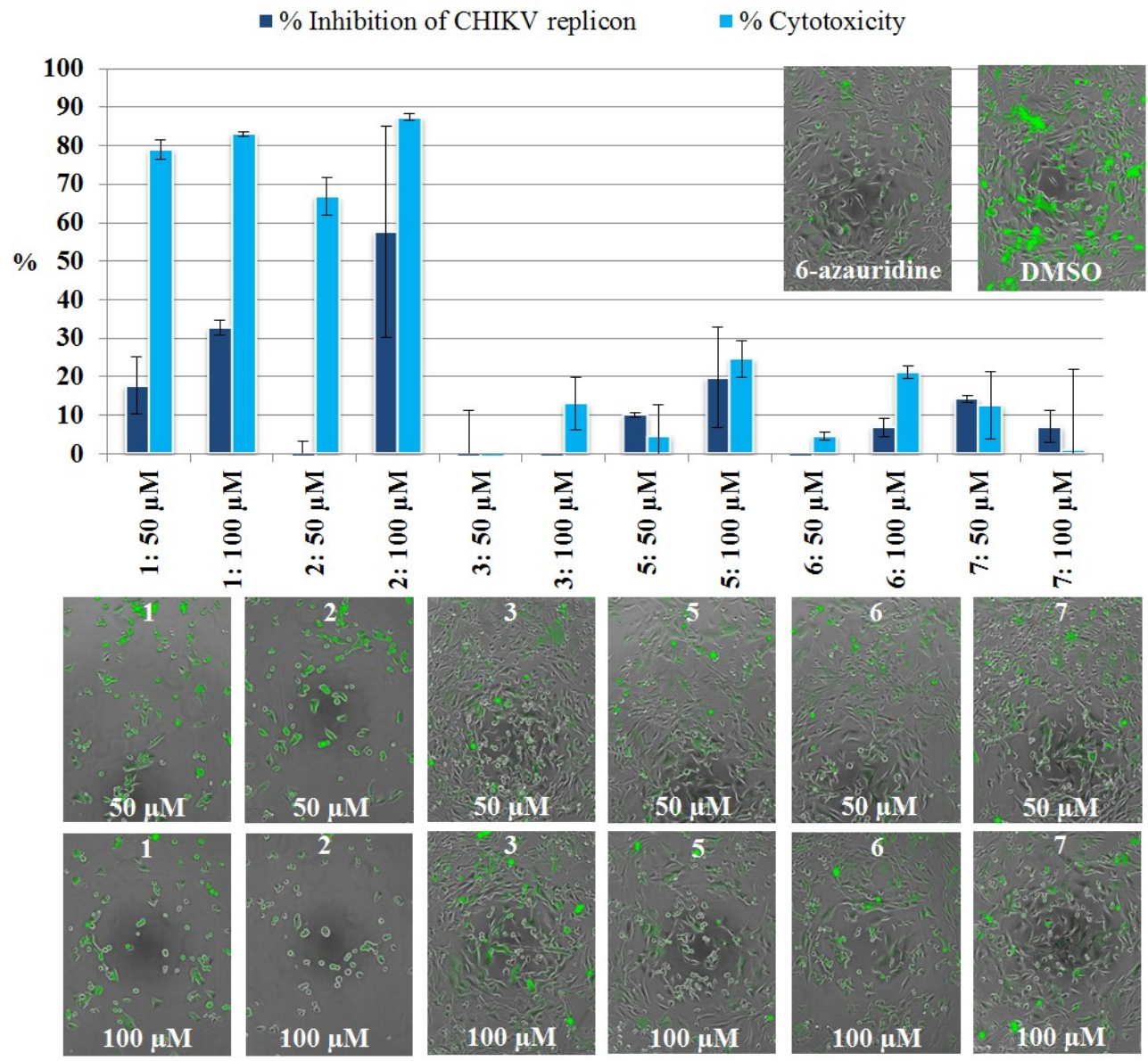

We can summarize that imaging in Cell-IQ ${ }^{\circledR}$ completes the information obtained by the primary detection techniques. In the present study, the imaging studies guided us to a more thorough investigation of the cytotoxic properties of the compounds obtained from S. kavarattiensis. As a conclusion, a marked CHIKV replicon inhibitory potential was found for the crude extracts of S. kavarattiensis, whereas Compounds $\mathbf{1}$ and $\mathbf{2}$ exhibited moderate inhibition of the CHIKV replicon along with prevailing cytotoxic activity.

\subsection{Anti-Inflammatory Activity of Isolated Compounds}

The biological activity of isolated Compounds 1-4 and $\mathbf{6}$ was tested by using primary microglial cell cultures. Microglial cells in untreated cell cultures usually appeared as ramified cells homogeneously distributed in the cultures. These ramified microglial (RM) cells, resembling the ramified type of 
microglia in vivo, displayed a pleomorphic cell body with a variable number of branching processes, sometimes with a spiny-like appearance. The cells were usually found as isolated cells without forming cell clusters. Apart from the RM, a number of amoeboid microglia (AM) was also distinguished. AM were smaller than RM and displayed pseudopodia and/or filopodia instead of cell processes. The AM cell density in non-treated cell cultures (NTCC) was about $85 \%$ lower than in lipopolysaccharide (LPS)-treated cultures (TC). After treatment with three different concentrations $(1.0 \mu \mathrm{g} / \mathrm{mL} ; 2.5 \mu \mathrm{g} / \mathrm{mL}$ and $5.0 \mu \mathrm{g} / \mathrm{mL}$ ) of Compounds $\mathbf{1}-\mathbf{4}$ and $\mathbf{6}$, significant RM and AM mean differences were observed in cultures treated with $2.5 \mu \mathrm{g} / \mathrm{mL}(7.2 \mu \mathrm{M})$ and $5.0 \mu \mathrm{g} / \mathrm{mL}(14.4 \mu \mathrm{M})$ of 2 (Figure 5). The observed results suggest that $\mathbf{2}$ was able to induce a shift from AM to RM shapes. Since AM cells are mainly activated cells, we conclude that this compound shows the ability to modulate an immune response and could interfere with the progression of chronic neurodegenerative diseases, although the underlying mechanisms are still unclear.

Figure 5. The effects on primary microglial cells in LPS-treated cultures (TC), non-treated cell cultures (NTCC) and after stimulation of LPS-treated cultures with different concentrations ( $1 \mu \mathrm{g} / \mathrm{mL}, 2.5 \mu \mathrm{g} / \mathrm{mL}$ and $5 \mu \mathrm{g} / \mathrm{mL}$ ) of Compounds $\mathbf{1}-\mathbf{4}$ and $\mathbf{6}$. In the healthy CNS, microglial cells have a highly ramified morphology with thin processes. Microglia, in this surveillance state, have been defined as ramified microglia. In contrast, reactive microglia (i.e., microglia that are no longer ramified microglia) can adopt different morphologies, including a hypertrophic cell with enlarged processes or an amoeboid macrophage-like morphology. Microglial cell density quantification (number of cells/field) in the treated and untreated primary microglial cell cultures shows the ability of Compound 2 at $2.5 \mu \mathrm{g} / \mathrm{mL}$ and $5.0 \mu \mathrm{g} / \mathrm{mL}$ to significantly reduce the number of activated amoeboid cells ( $p<0.05$ with respect to the TC control) and increase the number of ramified/resting cells ( $p<0.05$ with respect to the TC control).
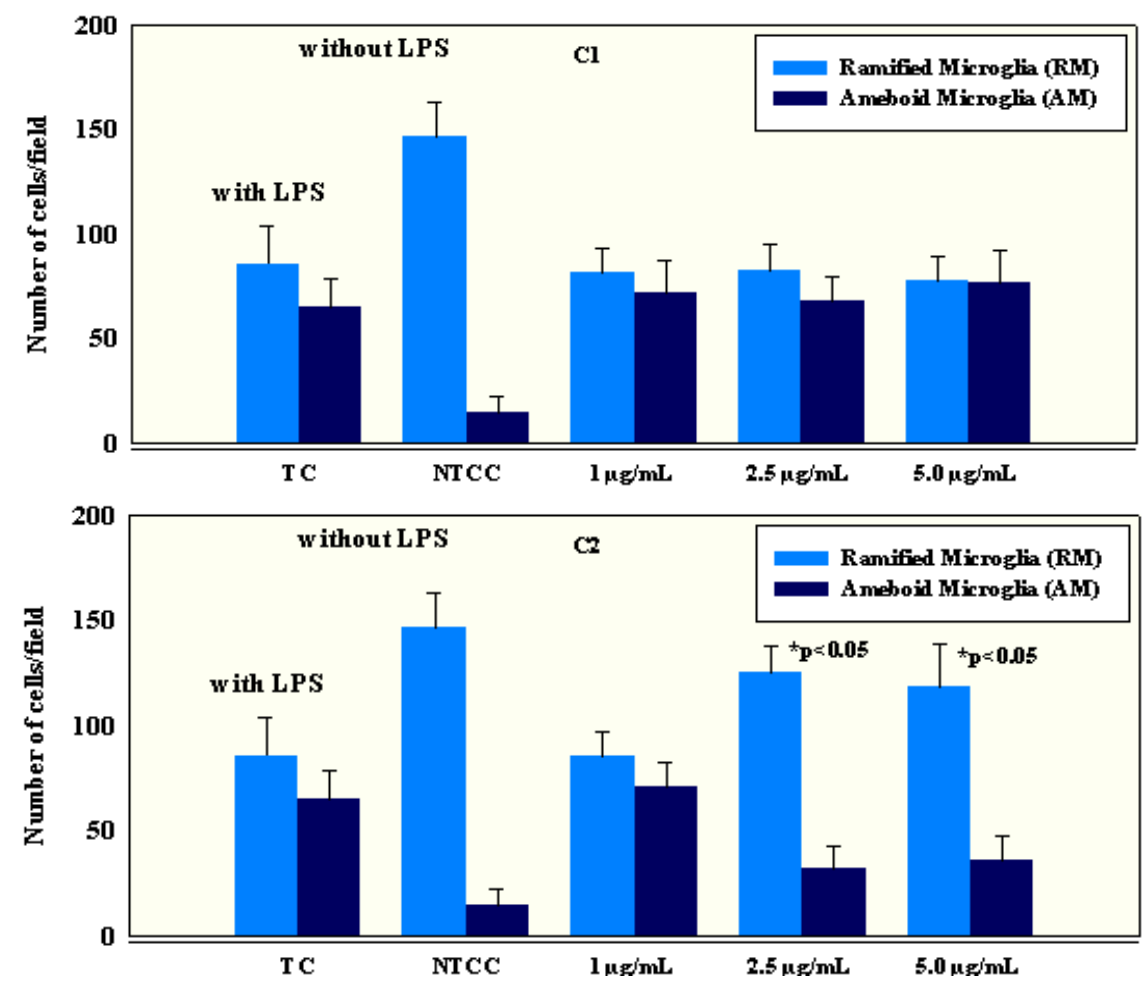
Figure 5. Cont.
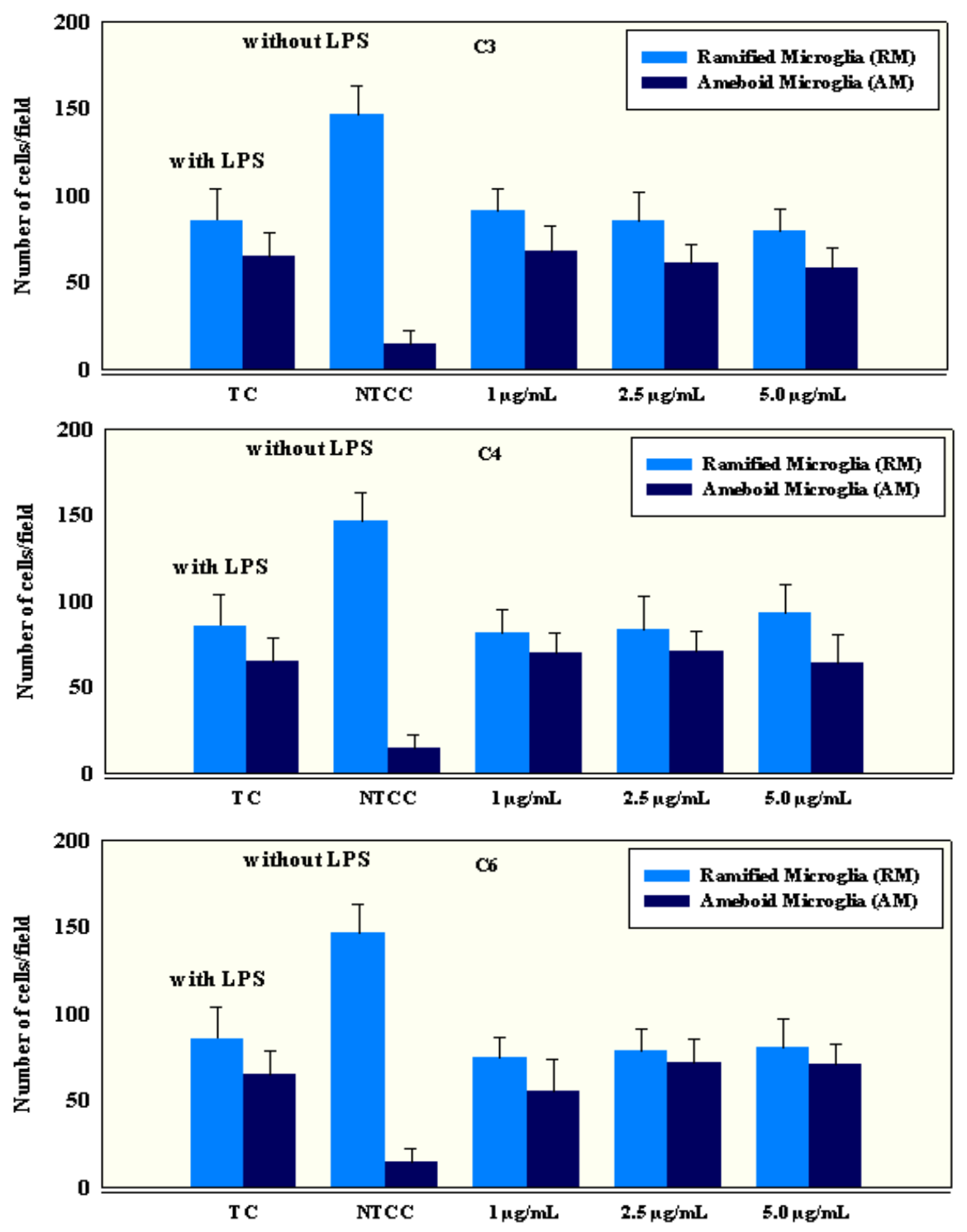

Microglia have the capacity to release a large number of substances that can be detrimental to the surrounding neurons, including glutamate, ATP, reactive oxygen species and pro-inflammatory cytokines. In glial cultures, different pro- and anti-inflammatory cytokines, as well as reactive oxygen and nitrogen species, are produced in response to LPS treatment. These factors are involved in the inflammatory response of reactive glial cells and the resolution of the inflammation. IL-10 is a cytokine with main immunoregulatory and anti-inflammatory properties. Several studies have shown the inhibitory effect of IL-10 treatment on the production of pro-inflammatory cytokines by reactive glia in response to LPS [46,47]. In addition to the morphological changes, cytokine release in supernatants was also quantified both in treated and control microglial cultures. The levels of pro-inflammatory cytokines, such as IL-1 $\beta$, IL-6, IL-8, IL-18 and TNF- $\alpha$, were significantly $(p<0.05)$ elevated (Table 2) in primary microglial cultures treated with LPS compared to controls. A significant difference was observed in the levels of pro-inflammatory cytokines IL-1 $\beta$, IL-6, IL-8, IL-18, TNF- $\alpha$, as well as in anti-inflammatory cytokines, such as IL-4 and IL-10, between Compound 2 at concentrations of $2.5 \mu \mathrm{g} / \mathrm{mL}(7.2 \mu \mathrm{M})$ and $5.0 \mu \mathrm{g} / \mathrm{mL}(14.4 \mu \mathrm{M})$ and the controls (Table 2). 
Table 2. Cytokine release $(\mathrm{pg} / \mathrm{mL})$ in the supernatants of primary microglial cells after $72 \mathrm{~h}$ of stimulation with different concentrations $(\mathrm{C} 1: 1.0 \mu \mathrm{g} / \mathrm{mL} ; \mathrm{C} 2: 2.5 \mu \mathrm{g} / \mathrm{mL}$; and C3: $5.0 \mu \mathrm{g} / \mathrm{mL}$ ) of Compounds $\mathbf{1}-\mathbf{4}$ and $\mathbf{6}$.

\begin{tabular}{cccccccc}
\hline & IL-1 $\beta$ & IL-6 & IL-8 & IL-18 & TNF- $\alpha$ & IL-4 & IL-10 \\
\hline LPS-treated (TC) $(1 \mu \mathrm{g} / \mathrm{mL})$ & $1.05 \pm 0.06$ & $13.5 \pm 1.2$ & $257 \pm 5.7$ & $325 \pm 8.4$ & $34.5 \pm 12.2$ & $1.4 \pm 2.4$ & $1.6 \pm 2.1$ \\
Non-treated (NTCC) (Medium) & $0.05 \pm 0.02$ & $1.5 \pm 0.8$ & $7 \pm 1.1$ & $8 \pm 1.3$ & $5 \pm 1.8$ & $7.3 \pm 0.05$ & $8.1 \pm 0.08$ \\
$\mathbf{1}(\mathrm{C} 1)$ & $1.04 \pm 0.08$ & $14.2 \pm 1.8$ & $256 \pm 12$ & $319 \pm 8.1$ & $33.5 \pm 11.2$ & $1.9 \pm 0.9$ & $7.6 \pm 1.6$ \\
$\mathbf{1}(\mathrm{C} 2)$ & $1.09 \pm 0.1$ & $11.7 \pm 1.2$ & $239 \pm 5$ & $318 \pm 7.5$ & $31.2 \pm 9.2$ & $2.1 \pm 0.8$ & $8.2 \pm 1.8$ \\
$\mathbf{1}(\mathrm{C} 3)$ & $1.08 \pm 0.05$ & $13.5 \pm 1.4$ & $241 \pm 7$ & $315 \pm 8.1$ & $33.6 \pm 11.1$ & $1.9 \pm 0.4$ & $8.7 \pm 2.1$ \\
$\mathbf{2 ( C 1 )}$ & $1.08 \pm 0.02$ & $12.1 \pm 0.9$ & $249 \pm 13$ & $326 \pm 4.9$ & $34.1 \pm 9.1$ & $2.1 \pm 0.9$ & $7.9 \pm 3.4$ \\
$\mathbf{2 ( C 2 )}$ & $0.07 \pm 0.04 *$ & $7.8 \pm 1.4 *$ & $123 \pm 11 *$ & $187 \pm 14 *$ & $12.3 \pm 3.4 *$ & $15.5 \pm 2.3 *$ & $17.4 \pm 2.3 *$ \\
$\mathbf{2 ( C 3 )}$ & $0.08 \pm 0.06 *$ & $8.5 \pm 1.3 *$ & $108 \pm 9 *$ & $155 \pm 11 *$ & $9.8 \pm 3.3 *$ & $18.4 \pm 1.8 *$ & $18.5 \pm 1.9 *$ \\
$\mathbf{3 ( C 1 )}$ & $1.1 \pm 0.05$ & $12.9 \pm 1.1$ & $247 \pm 8$ & $312 \pm 8.2$ & $33.6 \pm 11.2$ & $1.5 \pm 0.9$ & $7.5 \pm 1.4$ \\
$\mathbf{3 ( C 2 )}$ & $1.3 \pm 0.06$ & $11.5 \pm 1.3$ & $237 \pm 4$ & $321 \pm 7.8$ & $24.5 \pm 6.9$ & $1.6 \pm 0.8$ & $6.8 \pm 1.5$ \\
$\mathbf{3 ( C 3 )}$ & $1.2 \pm 0.05$ & $13.2 \pm 1.2$ & $244 \pm 11$ & $318 \pm 7.6$ & $35.4 \pm 12.4$ & $1.7 \pm 0.5$ & $6.9 \pm 1.5$ \\
$\mathbf{4 ( C 1 )}$ & $1.01 \pm 0.04$ & $12.1 \pm 1.3$ & $247 \pm 8$ & $312 \pm 8.2$ & $33.2 \pm 2.8$ & $2.2 \pm 0.2$ & $8.4 \pm 2.6$ \\
$\mathbf{4 ( C 2 )}$ & $1.02 \pm 0.04$ & $14.1 \pm 1.1$ & $247 \pm 8$ & $312 \pm 8.2$ & $29.8 \pm 2.5$ & $2.3 \pm 0.5$ & $7.9 \pm 2.5$ \\
$\mathbf{4 ( C 3 )}$ & $1.01 \pm 0.02$ & $12.1 \pm 1.3$ & $247 \pm 8$ & $312 \pm 8.2$ & $32.5 \pm 3.7$ & $1.8 \pm 0.2$ & $7.8 \pm 3.2$ \\
$\mathbf{6 ( C 1 )}$ & $1.07 \pm 0.07$ & $13.2 \pm 0.2$ & $247 \pm 8$ & $312 \pm 8.2$ & $31.2 \pm 2.9$ & $1.8 \pm 0.6$ & $8.5 \pm 3.2$ \\
$\mathbf{6 ( C 2 )}$ & $1.1 \pm 0.05$ & $12.1 \pm 0.9$ & $247 \pm 8$ & $312 \pm 8.2$ & $30.6 \pm 2.6$ & $1.9 \pm 0.6$ & $7.8 \pm 2.2$ \\
$\mathbf{6}(\mathrm{C} 3)$ & $1.09 \pm 0.02$ & $11.8 \pm 1.2$ & $247 \pm 8$ & $312 \pm 8.2$ & $32.3 \pm 3.2$ & $1.9 \pm 0.9$ & $7.5 \pm 2.1$ \\
\hline
\end{tabular}

$* p<0.05$.

Table 3. In vitro cytotoxic effects $\left(\mathrm{IC}_{50}\right)$ on primary microglial cell cultures and the inhibitory effect on LPS-induced pro-inflammatory cytokine release of Compounds 1-4 and 6. Each value represents the mean of triplicate determinations.

\begin{tabular}{|c|c|c|c|c|c|c|c|c|}
\hline Sample & Cytotoxicity & IL-1及 & IL-6 & IL-8 & IL-18 & TNF- $\alpha$ & IL-4 & IL-10 \\
\hline \multicolumn{9}{|c|}{$\mathrm{IC}_{50}(\mu \mathrm{g} / \mathrm{mL})$} \\
\hline 1 & $>100$ & $>12.5$ & $>12.5$ & $>12.5$ & $>12.5$ & $>12.5$ & $>12.5$ & $>12.5$ \\
\hline 2 & $>100$ & 0.5 & 2.2 & 2.3 & 2.9 & 1.7 & 0.5 & 0.5 \\
\hline 3 & $>100$ & $>12.5$ & $>12.5$ & $>12.5$ & $>12.5$ & $>12.5$ & $>12.5$ & $>12.5$ \\
\hline 4 & $>100$ & $>12.5$ & $>12.5$ & $>12.5$ & $>12.5$ & $>12.5$ & $>12.5$ & $>12.5$ \\
\hline 6 & $>100$ & $>12.5$ & $>12.5$ & $>12.5$ & $>12.5$ & $>12.5$ & $>12.5$ & $>12.5$ \\
\hline Tamoxifen & 3.60 & ND & ND & ND & ND & ND & ND & ND \\
\hline Prednisolone & ND & 12 & 13 & 15 & 16 & 10 & 20 & 15 \\
\hline
\end{tabular}

ND: not determined.

Furthermore, the inhibition of cytokine release and the cytotoxicity towards primary microglial cell cultures was measured at several compound concentrations to determine the $\mathrm{IC}_{50}$ values (Table 3 ). Compounds 1-4 and 6 were tested for cytotoxicity at seven concentrations ranging from 1.56 to $100 \mu \mathrm{g} / \mathrm{mL}$ and for cytokine release at six concentrations ranging from 0.39 to $12.5 \mu \mathrm{g} / \mathrm{mL}$. Tamoxifen and prednisolone were used as positive controls in the MTT assay and in cytokine quantification, respectively. Similarly to previous data presented in Table 2, Compound 2 showed effective and dose-dependent inhibition of cytokine release. As demonstrated in Table 3, the $\mathrm{IC}_{50}$-values for the inhibition of cytokine release for Compound 2 ranged from $0.5 \mu \mathrm{g} / \mathrm{mL}(1.4 \mu \mathrm{M})$ to $2.9 \mu \mathrm{g} / \mathrm{mL}$ 
$(8.3 \mu \mathrm{M})$; all of them being markedly lower than those of the positive control prednisolone. The $\mathrm{IC}_{50}$-values for cytotoxic activity for each of the tested compounds, 1-4 and $\mathbf{6}$, turned out to be higher than the maximal test concentration of $100 \mu \mathrm{g} / \mathrm{mL}$, and the cytotoxicity was thus not influencing the observed anti-inflammatory properties. In accordance with these results, we suggest that among new anti-inflammatory agents, special attention should be paid to Compound $\mathbf{2}$.

\subsection{Bioactivity Potential and Structure-Activity Relationships of Metabolites from S. kavarattiensis}

The anti-inflammatory properties of metabolites from Sinularia species have previously been reported in numerous studies [19-24]. Our results imply that Compound 2, in addition to anti-inflammatory activity, also possesses promising immunomodulatory activity. Takaki and coworkers described the anti-inflammatory effects of $\mathbf{2}$ by demonstrating the inhibition of LPS-induced TNF- $\alpha$ production in murine macrophage-like cells [48]. Our results show that the anti-inflammatory activity of 2, except for the inhibition of TNF- $\alpha$ release, also takes place through the inhibition of the release of cytokines that belong to the interleukin family.

The CHIKV replicon-inhibiting potential of isolated Compounds 1-3 and 5-7 was not as striking as the activity observed for the crude extracts and the enriched fractions of S. kavarattiensis. On the one hand, the reason behind this observation may be the synergetic activity of the compounds in the extracts and fractions, which leads to higher inhibition percentages than those exhibited by each compound separately. On the other hand, the primary test concentration for the extracts and fractions was as high as $100 \mu \mathrm{g} / \mathrm{mL}$, whereas the test concentration of the pure compounds in the CHIKV replicon model, $100 \mu \mathrm{M}$, equals a concentration of $35 \mu \mathrm{g} / \mathrm{mL}$ in the case of Compounds 1 and 2 .

5-epi-Sinuleptolide 1 and sinuleptolide 2 share a common $\alpha$ - $\beta$-unsaturated- $\gamma$-butyrolactone moiety, which is recognized to play a pivotal role in the interactions with unidentified molecular targets [49,50]. The inactivity in both the CHIKV replicon model and the anti-inflammatory assays of Compounds 3-7 that lack this functionality strongly suggests the involvement of an electrophilic conjugated function in $\mathbf{1}$ and $\mathbf{2}$, which could act as a Michael acceptor toward reactive lysine or cysteine residues in the biological targets. Compound $\mathbf{1}$ and $\mathbf{2}$ only differ from each other regarding the configuration of one stereogenic center. The inactivity in the anti-inflammatory assays of Compound $\mathbf{1}$ is, however, not surprising. The covalent interaction with protein targets requires a correct positioning through specific the non-covalent interactions of the active functional group within the active site of the biological target.

The observed cytotoxicity against the BHK-CHIKV-NCT at high concentrations of Compounds $\mathbf{1}$ and 2 could be explained in terms of their potential Michael acceptor activity, which can lead to cell damage and general toxicity [51]. The predominating cytotoxic properties at the effective concentrations make further exploration of the antiviral potential of these compounds challenging. On the contrary, Compound 2 inhibited the release of pro-inflammatory cytokines and displayed immunomodulatory activity at concentrations that caused no cytotoxicity against the primary microglial cells used in our study. Huang and coworkers [26] have described the cytotoxic properties of the acetate of $\mathbf{1}$ (5-epi-sinuleptolide acetate) at low concentrations against a panel of cancer cell lines, demonstrating apoptosis induction and cell cycle arrest to lie behind the cytotoxic effects. Furthermore, Liang and coworkers has demonstrated that $\mathbf{1}$ triggers cell cycle arrest and apoptosis in skin cancer cells at low 
concentrations [44]. Liang et al. studied the cytotoxicity of both $\mathbf{1}$ and $\mathbf{2}$ and found that $\mathbf{1}$ causes more prominent cytotoxic effects with lower $\mathrm{IC}_{50}$-values against the studied cancer cell lines. Our results imply that at $50 \mu \mathrm{M}$ concentration, $\mathbf{1}$ is slightly more cytotoxic to the BHK-CHIKV-NCT cells than 2; however, at $100 \mu \mathrm{M}$, the differences in cytotoxicity are minor. The impact of cellular confluence is nevertheless critical. Our results show that cell cultures that have reached confluence before the treatment with compounds is started are more resistant to the cytotoxic effects.

\section{Experimental Section}

\subsection{General Experimental Procedures}

Specific rotations were measured on a PerkinElmer 243 B polarimeter. High-resolution ESI-MS spectra were performed with a Micromass QTOF Micromass spectrometer. ESI-MS experiments were performed on an Applied Biosystem API 2000 triple-quadrupole mass spectrometer. NMR spectra were obtained on Varian Inova $700 \mathrm{MHz}$ spectrometer $\left({ }^{1} \mathrm{H}\right.$ at $700 \mathrm{MHz},{ }^{13} \mathrm{C}$ at $175 \mathrm{MHz}$, respectively) equipped with a Sun hardware, $\delta(\mathrm{ppm}), J$ in Hz; and spectra referred to DMSO- $d_{6}\left(\delta_{\mathrm{H}} 2.50, \delta_{\mathrm{C}} 39.5\right)$ as the internal standard. Through-space ${ }^{1} \mathrm{H}$ connectivities were evidenced using a ROESY experiment with a mixing time of 200 and $300 \mathrm{~ms}$. HPLC was performed using a Waters Model 510 pump equipped with a Waters Rheodyne injector and a differential refractometer, model 401. Silica gel (200-400 mesh) from Macherey-Nagel Company (Düren, Germany) was used for flash chromatography. The purities of compounds were determined to be greater than $95 \%$ by HPLC.

\subsection{Biological Material}

Soft coral, Sinularia kavarattiensis Alderslade \& Prita, was collected off the coast of Rameshwaram, Tamil Nadu, India (Latitude: 9०16'60'N Longitude: 79¹7'60"E) in December 2010. It was frozen at $-20{ }^{\circ} \mathrm{C}$ and transferred to the Council of Scientific and Industrial Research-National Institute of Oceanography (CSIR-NIO) Laboratory, Goa, India. The organism was identified by Panachamoottil Abraham Thomas, Emeritus Scientist, Vizhingam Research Center, Central Marine Fisheries Research Institute, Kerala, India. A voucher specimen (14S021) is deposited at the CSIR-NIO. Four hundred grams of freeze-dried organism were extracted four times with $80 \%$ methanol $(500 \mathrm{~mL})$ each time to obtain $23 \mathrm{~g}$ of the crude methanolic extract. The same sample was then extracted three times with methanol:chloroform $(1: 1)$. The extracts were concentrated at $30{ }^{\circ} \mathrm{C}$ using a Rotavapor and a vacuum pump.

\subsection{Chemical Characterization}

The crude methanolic extract (18.061 g) was subjected to a modified Kupchan's partitioning procedure [39], as follows. The methanol extract was dissolved in a mixture of $\mathrm{MeOH} / \mathrm{H}_{2} \mathrm{O}$ containing $10 \% \mathrm{H}_{2} \mathrm{O}$ and partitioned against $n$-hexane to give $2.9 \mathrm{~g}$ of the crude extract. The water content $(\% v / v)$ of the $\mathrm{MeOH}$ extract was adjusted to $30 \%$ and partitioned against $\mathrm{CHCl}_{3}$ to give $3.2 \mathrm{~g}$ of the crude extract. The aqueous phase was concentrated to remove $\mathrm{MeOH}$ and, then, subsequently extracted with ethyl acetate $(0.29 \mathrm{~g})$ and with $n$ - $\mathrm{BuOH}(1.6 \mathrm{~g})$. 
The $\mathrm{CHCl}_{3}$ extract (3.2 g) was fractionated by silica gel MPLC using a solvent gradient system from $\mathrm{CH}_{2} \mathrm{Cl}_{2}$ to $\mathrm{MeOH}$. The fraction eluted with $\mathrm{CH}_{2} \mathrm{Cl}_{2} / \mathrm{MeOH}$ 995:5 (138 mg) contained pure ent-germacra-4(15),5E,10(14)-trien-1 $\beta$-ol 5 (19 $\mathrm{mg} ; 0.005 \%$ yield). The fraction eluted with $\mathrm{CH}_{2} \mathrm{Cl}_{2} / \mathrm{MeOH}$ 99:1 (101 mg) was further purified by HPLC on a Nucleodur 100-5 $\mathrm{C} 18$ (5 $\mu \mathrm{m}$; $4.6 \mathrm{~mm}$ i.d. $\times 250 \mathrm{~mm}$ ) with $55 \% \mathrm{MeOH} / \mathrm{H}_{2} \mathrm{O}$ as the eluent (flow rate $1 \mathrm{~mL} / \mathrm{min}$ ) to give $1.3 \mathrm{mg}$ of kavaranolide $7\left(t_{\mathrm{R}}=8.5 \mathrm{~min}, 0.0003 \%\right.$ yield $), 3.9 \mathrm{mg}$ of ineleganolide $6\left(t_{\mathrm{R}}=10 \mathrm{~min} ; 0.001 \%\right.$ yield$)$, $2.4 \mathrm{mg}$ of scabrolide D $3\left(t_{\mathrm{R}}=15.5 \mathrm{~min} ; 0.0006 \%\right.$ yield $)$ and $1.0 \mathrm{mg}$ of norcembranoid $4\left(t_{\mathrm{R}}=19.5 \mathrm{~min}\right.$; $0.0003 \%$ yield). The other fraction eluted with $\mathrm{CH}_{2} \mathrm{Cl}_{2} / \mathrm{MeOH} 99: 1$ (125 mg) was further purified by HPLC on a Nucleodur 100-5 C18 (5 $\mu$; $4.6 \mathrm{~mm}$ i.d. $\times 250 \mathrm{~mm})$ with $40 \% \mathrm{MeOH} / \mathrm{H}_{2} \mathrm{O}$ as the eluent (flow rate $1 \mathrm{~mL} / \mathrm{min}$ ) to give $13.0 \mathrm{mg}$ of 5-epi-sinuleptolide 1 ( $t_{\mathrm{R}}=20 \mathrm{~min} ; 0.003 \%$ yield) and $8.0 \mathrm{mg}$ of sinuleptolide $2\left(t_{\mathrm{R}}=24 \mathrm{~min} ; 0.002 \%\right.$ yield $)$. The reported percentage yields are referred to $400 \mathrm{~g}$ of freeze-dried material.

\subsection{Characteristic Data for Natural Compounds}

NMR data for Compounds 1-6 as previously reported [29,30,32-35].

Kavaranolide 7: white amorphous solid; $[\alpha]_{\mathrm{D}}{ }^{25}+14.5$ (c $\left.0.13, \mathrm{MeOH}\right) ;{ }^{1} \mathrm{H}$ and ${ }^{13} \mathrm{C} \quad \mathrm{NMR}$ spectroscopic data in DMSO- $d_{6}$ given in Table 1; ESIMS: $m / z 329.1[\mathrm{M}-\mathrm{H}]^{-}$. HRMS (ESI) $m / z$ $329.1381[\mathrm{M}-\mathrm{H}]^{-}$(calcd. for $\mathrm{C}_{19} \mathrm{H}_{21} \mathrm{O}_{5} \mathrm{~m} / \mathrm{z} 329.1389$ ).

\subsection{Evaluation of Anti-CHIKV Replicon Properties}

\subsubsection{BHK-CHIKV-NCT Cell Culture}

A stable BHK21 cell line (BHK-CHIKV-NCT), described by Pohjala and coworkers [52], was used for studying potential anti-CHIKV activity. The cell line harbors the CHIKV replicon and continuously expresses the selection marker puromycin acetyltransferase and two marker proteins (enhanced green fluorescent protein (EGFP) and Renilla luciferase $(R l u c)$ ) for detecting the inhibition of the viral replicon. The BHK-CHIKV-NCT cells were subcultured three times a week and maintained at $37{ }^{\circ} \mathrm{C}, 5 \% \mathrm{CO}_{2}$ and 95\% humidity in Dulbecco's Modified Eagle's Medium with high glucose and L-glutamine $\left(\right.$ Gibco $^{\circledR}$ ) supplemented with $7.5 \%$ fetal bovine serum (FBS), 2\% tryptose-broth phosphate, $1 \mathrm{mM}$ sodium pyruvate, $100 \mathrm{IU} / \mathrm{mL}$ penicillin, $100 \mu \mathrm{g} / \mathrm{mL}$ streptomycin and $5 \mu \mathrm{g} / \mathrm{mL}$ puromycin.

\subsubsection{CHIKV Replicon Assay, Rluc Detection}

BHK-CHIKV-NCT cells were seeded onto opaque-white, clear-bottomed 96-well plates (PerkinElmer Inc., Waltham, MA, USA) with a cell density of 40,000 cells/well. The cells were exposed to test samples after $24 \mathrm{~h}$ of incubation at $37{ }^{\circ} \mathrm{C}$. The sample stocks were diluted into assay medium consisting of Dulbecco's Modified Eagle's Medium with high glucose and L-glutamine $\left(\right.$ Gibco $\left.^{\circledR}\right)$ supplemented with $5 \%$ fetal bovine serum (FBS), $1 \mathrm{mM}$ sodium pyruvate, $100 \mathrm{IU} / \mathrm{mL}$ penicillin and $100 \mu \mathrm{g} / \mathrm{mL}$ streptomycin. Puromycin was excluded from the assay medium to avoid puromycin-induced toxicity. The exposure time to test samples was $48 \mathrm{~h}$, after which the Rluc expression was determined by using a Renilla luciferase assay kit (Promega, Madison, WI, USA), 
according to the manufacturer's instructions. The luminescence signal was recorded using a Varioskan Flash plate reader (Thermo Fischer Scientific, Vantaa, Finland) with a measurement time of $1 \mathrm{~s}$ and automatic dynamic range settings. The primary test concentration for crude extracts was $100 \mu \mathrm{g} / \mathrm{mL}$ $(n=3)$. The percentage of inhibition of the viral replicon was calculated by comparing the sample signal to the yielded maximum signal (DMSO vehicle in assay medium), and the activity threshold was set at $>50 \%$ inhibition of Rluc expression.

The screening assay was optimized for Rluc detection and validated by dose-response experiments for the positive control, 6-azauridine. The dose-response curve for 6-azauridine determined by Rluc detection showed sigmoidal, dose-dependent reduction in the marker level, with an $\mathrm{IC}_{50}$ value of $2 \mu \mathrm{M}$. The 6-azauridine concentration used as a positive control on every assay plate was $10 \mu \mathrm{M}$, which caused an average inhibition of $69 \%$. The signal-to-background ratio (S/B) and signal-to-noise ratio $(\mathrm{S} / \mathrm{N})$ were calculated for each plate as a measure of assay quality [53]. DMSO in assay medium represented the maximum signal and wells with only medium and reagents the background.

\subsubsection{Cytotoxicity Assay}

The viability of BHK-CHIKV-NCT cells was determined after treatment with hit samples in order to exclude possible false positives. The test conditions were identical to those described for the Rluc assay. After $48 \mathrm{~h}$ of exposure to the samples, cell viability was determined by ATP quantitation using a CellTiter GLO ${ }^{\circledR}$ Luminescent Cell Viability Assay kit (Promega, Madison, WI, USA). Briefly, the cells were equilibrated to room temperature and washed with $100 \mu \mathrm{L}$ of phosphate buffered saline solution, after which $50 \mu \mathrm{L}$ of CellTiter GLO ${ }^{\circledR}$ Reagent and $50 \mu \mathrm{L}$ of assay medium were added. The plate was subjected to shaking for $2 \mathrm{~min}$ to induce cell lysis, and after $10 \mathrm{~min}$, the luminescence was measured by using a Varioskan Flash plate reader.

Each sample was tested in triplicate, and the cytotoxic effect of test samples was determined as a percentage by using the maximum signal (DMSO vehicle in the assay medium) as the reference and cells with no reagent added as the background value. The cytotoxicity assay was validated by dose-response experiments for the positive control, polymyxin B, which showed dose-dependent cytotoxicity. The $\mathrm{ED}_{50}$ for the cytotoxic activity of polymyxin B was determined as $5900 \mathrm{IU} / \mathrm{mL}$. The polymyxin B concentration used in the experiments was $10,000 \mathrm{IU} / \mathrm{mL}$ and caused an average toxicity of $93 \%$.

\subsubsection{CHIKV Replicon Assay, Live Cell Imaging}

The effects of the control compounds and test samples on proliferation, morphology and expression of EGFP in BHK-CHIKV-NCT cells was analyzed in a continuous cell culturing platform with integrated optics (Cell-IQ ${ }^{\circledR}$ Fluorescence, Chip-Man Technologies Ltd., Tampere, Finland). The expression of EGFP is an equally valid marker as Rluc for the inhibition of the CHIKV replicon.

The test conditions were optimized by evaluating different imaging settings and cell densities. The cells were seeded onto clear-bottomed black-framed 96-well plates (PerkinElmer Inc., Waltham, MA, USA) with a density of 3000 cells/well and incubated for $24 \mathrm{~h}$ at $37{ }^{\circ} \mathrm{C}$ before starting the treatment. The samples were diluted into assay medium, as for the Rluc and cytotoxicity assays. Each sample was tested in triplicate. After starting the treatment, phase-contrast and fluorescent images were 
taken with 30 min intervals for $48 \mathrm{~h}$ using a 10× objective. Before starting the imaging, a Cell-Secure Lid (Chip-Man Technologies, Tampere, Finland) equipped with a gas input connector and a sterile $0.2-\mu \mathrm{m}$ filter was sealed to the plate. The plate was incubated at $37{ }^{\circ} \mathrm{C}$ using the manufacturer's default $\mathrm{CO}_{2}$ flow setting ( $8 \mathrm{~min}$ flow, $20 \mathrm{~min}$ pause, $30 \mathrm{~min}$ initial flow). For the phase contrast images, the $z$-stack was $17.60 \mu \mathrm{m}$ and the exposure time $10 \mathrm{~ms}$; for the fluorescent images, the default imaging settings for green fluorescent protein with binning $2 \times 2$ and an exposure time of $200 \mathrm{~ms}$ were applied.

Protocols for analyzing the images captured in Cell-IQ ${ }^{\circledR}$ were created according to the manufacturer's instructions using the Cell-IQ Analyser ${ }^{\circledR}$ software (Chip-Man Technologies, Tampere, Finland). Details on the creation of analysis protocols can be found in the Supplementary Information.

Figure 6. The effects of control compounds (DMSO vehicle, 6-azauridine, polymyxin B) on BHK-CHIKV-NCT cells imaged with Cell-IQ ${ }^{\circledR}$ and analyzed with Cell-IQ Analyser ${ }^{\circledR}$ software: Fluorescence and cell count at $1 \mathrm{~h}, 24 \mathrm{~h}$ and $48 \mathrm{~h}$ and combined fluorescent and phase contrast images for each time point. The number of viable cells is determined as the sum of cells classified as living and dividing.
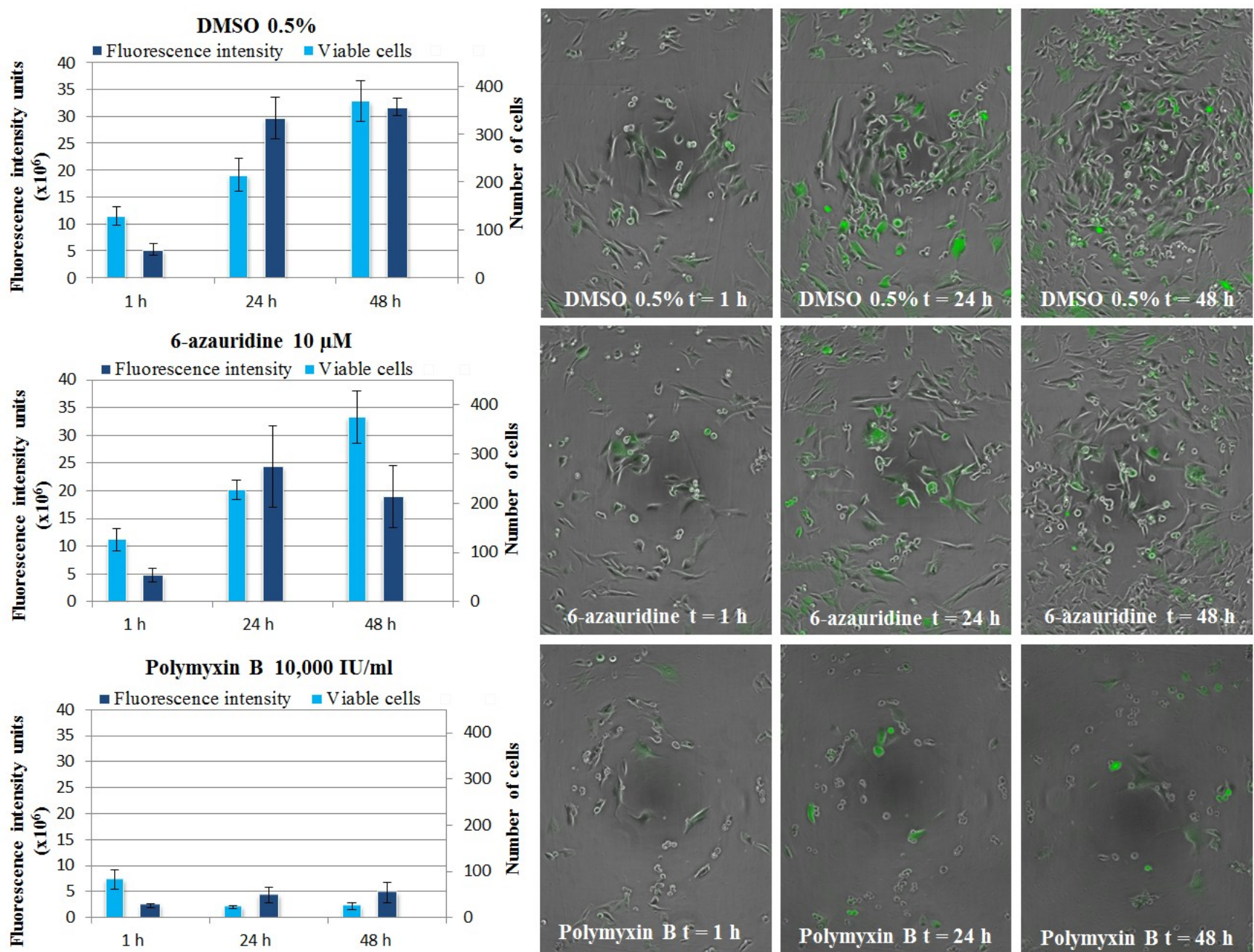

The experiments performed in Cell-IQ ${ }^{\circledR}$ were validated through tests on the control compounds used in the Rluc assay and the cytotoxicity assay: DMSO vehicle in the assay medium, 6-azauridine as a model antiviral agent and polymyxin B as a model cytotoxic agent. BHK-CHIKV-NCT cells treated 
with control compounds were imaged for $48 \mathrm{~h}$, after which the created analysis protocols were applied. The results of cell classification and fluorescence intensity analysis for BHK-CHIKV-NCT cells treated with control compounds are shown for three time points in Figure 6. Positive control 6-azauridine decreases the fluorescence intensity of the cells, without affecting cell morphology, whereas polymyxin B radically decreases both the number of viable cells and, as a consequence, the fluorescence intensity.

Percentages of CHIKV replicon inhibition based on fluorescence detection and cytotoxicity based on cell classification were calculated for each sample. To additionally increase the reliability, results reported for test samples are averages from two independent assays with 3 replicate wells each.

\subsection{Evaluation of Anti-Inflammatory Properties}

\subsubsection{Preparation of Microglial Primary Cell Cultures}

Primary microglial cell cultures were prepared from brains of newborn Wistar rats [54]. Ethics approval for the experiments was granted by the EBIOTEC Review Board (Valter Lombardi, Iván Carrera and Lucía Fernández-Novoa; Project Identification Code: Sinularia Project October 2013; approved 30 October 2013). The neocortex of one-day-old postnatal rats was aseptically dissected out, and the meninges and blood vessels were carefully removed. Following cutting in a medium containing $20 \%$ horse serum, the suspension was filtered through a $40-\mathrm{mm}$ filter and transferred as a single cell suspension to culture dishes, using $5.0 \mathrm{~mL}$ of medium per dish. The cultures were incubated at $37{ }^{\circ} \mathrm{C}$ in an atmosphere containing $5 \% \mathrm{CO}_{2}$. The culture medium consisted of Minimum Essential Medium Eagle, supplemented with L-glutamine, amino acids, vitamins, penicillin, gentamicin, sodium bicarbonate and $20 \%$ heat-inactivated horse serum. The medium was changed twice a week. After 1 week, the concentration of horse serum was reduced to $10 \%$. After sixteen days in culture, cells were treated with $1 \mu \mathrm{g} / \mathrm{mL}$ of lipopolysaccharide (LPS). After six hours, different concentrations $(1.0 \mu \mathrm{g} / \mathrm{mL}, 2.5 \mu \mathrm{g} / \mathrm{mL}$ and $5.0 \mu \mathrm{g} / \mathrm{mL}$ ) of Compounds $\mathbf{1 - 4}$ and $\mathbf{6}$ were added to each well, and plates were incubated for $72 \mathrm{~h}$ at $37{ }^{\circ} \mathrm{C}$ in an atmosphere containing $5 \% \mathrm{CO}_{2}$. Positive controls were treated only with LPS, while negative controls were treated with complete medium. After $72 \mathrm{~h}$ of incubation, cells were counted, and $2.5 \mathrm{~mL}$ of the supernatants were collected from each well and frozen at $-40{ }^{\circ} \mathrm{C}$ for cytokine analyses. All experiments were carried out twice.

\subsubsection{Cell Count}

Statistical analysis was carried out from three randomly chosen untreated dishes and three randomly chosen treated dishes. Microglial density values were obtained by counting 10 fields in the microglial area for each cell culture using a $20 \times$ objective. The ANOVA test was performed at the $95 \%$ significance level in order to contrast differences.

\subsubsection{Determination of Cytokine Concentration}

The supernatants obtained from cell cultures were analyzed for TNF- $\alpha$, IL-1 $\beta$, IL-4, IL-6, IL-8, IL-10 and IL-18 using commercially available ELISA kits following the manufacturers' instructions. 
All samples were assayed in duplicate, and equivocal results were repeated. The cytokine concentration was calculated from a standard curve of the corresponding recombinant cytokine.

\subsubsection{Determination of $\mathrm{IC}_{50}$ Values by Quantitation of Cytokine Release and Colorimetric Methyl} Thiazol Tetrazolium (MTT) Cytotoxicity Assay

The cytotoxicity of the compounds was measured by the colorimetric methyl thiazol tetrazolium (MTT) assay and scored as a percentage of the absorbance reduction of treated cultures versus untreated control cultures. Primary microglial cell cultures were seeded into 96-well microplates at $10^{4}$ cells per well and allowed to grow for $24 \mathrm{~h}$. The initial concentration of Compounds $\mathbf{1}-\mathbf{4}$ and $\mathbf{6}$ was $100 \mu \mathrm{g} / \mathrm{mL}$ in DMSO. The compounds were serially diluted in complete culture medium with two-fold dilutions $(100,50,25,12.5,6.25,3.12$ and $1.56 \mu \mathrm{g} / \mathrm{mL}$ for in vitro cytotoxicity; $12.5,6.25,3.12,1.56$, 0.78 and $0.39 \mu \mathrm{g} / \mathrm{mL}$ for cytokine release). Different concentrations of the compounds were added to each well, and Tamoxifen was used as a positive control, with concentrations ranging from 50 to $1.56 \mu \mathrm{g} / \mathrm{mL}$. Plates were incubated at $37{ }^{\circ} \mathrm{C}$ for $72 \mathrm{~h}$ under $5 \% \mathrm{CO}_{2}$ atmosphere. Then, the $50 \mu \mathrm{L}$ of MTT-PBS solution in culture medium were added to each well. The plates were further incubated for $4 \mathrm{~h}$ under the same conditions. The medium was then removed and replaced with $200 \mu \mathrm{L}$ of DMSO to solubilize the MTT formazan product. The solutions were shaken for $20 \mathrm{~min}$, and the absorbance was measured at $570 \mathrm{~nm}$. One hundred microliters of the supernatants collected after incubation were used for cytokine quantification, as described in Section 3.6.3, and prednisolone was used as a positive control. Each value represents the mean of triplicate determinations. The $\mathrm{IC}_{50}$ values were calculated from the compound concentration-response curves.

\subsubsection{Statistics}

The results are expressed as the mean \pm standard deviation. Paired and unpaired Student's $t$-tests were used to determine the significance of differences; a value of $p<0.05$ was considered statistically significant.

\section{Conclusions}

The investigation of bioactive natural products from an Indian soft coral, Sinularia kavarattiensis, led to the isolation of a novel norcembranoid, named kavaranolide (7), along with six known compounds (1-6). Despite its inactivity in the CHIKV replicon model, the isolation and characterization of kavaranolide (7) adds value to the outcomes of this study. Imaging experiments on the CHIKV replicon model with the isolated compounds indicated that both $\mathbf{1}$ and $\mathbf{2}$ show moderate activity against the CHIKV replicon, but also remarkable cytotoxic properties. The effects of the isolated compounds on primary microglial cells, on the contrary, clearly indicate that Compound $\mathbf{2}$ is able to regulate the morphology and function of surveying/resting microglia and to decrease the activation of microglia, which could contribute to the progression of chronic neurodegenerative diseases. Since Compound $\mathbf{2}$ also shows potential anti-inflammatory properties based on the effect on cytokine release, it is possible to hypothesize that it may have the capacity to reduce the release of a large number of substances that can be detrimental to the surrounding neurons and finally contribute to 
a CNS homeostasis. In recent years, several natural products isolated from herbal plants [55] were proven to act as inhibitors of microglial neurotoxicity. This study represents the first report of a marine natural product with modulatory activity on neuroinflammation.

\section{Acknowledgments}

The research leading to these results has received funding from the European Union Seventh Framework Programme under grant agreement No. FP7-KBBE-2009-3-245137 (MAREX). We thank Harri Jäälinoja (Light Microscopy Unit, University of Helsinki) for the excellent assistance in the design and result analysis of the live-cell imaging studies.

\section{Author Contributions}

Katja-Emilia Lillsunde, Dorota A. Nawrot and Päivi Tammela designed and performed the CHIKV replicon experiments and the live cell imaging studies and analyzed the results. Simona De Marino and Carmen Festa achieved whole chemical experiments, including isolation, NMR analysis and structure investigation. Angela Zampella and Maria Valeria D'Auria contributed to the organization and discussion of isolation and structural characterization. Lisette D'Souza, Harshada Adel and Supriya Tilvi contributed to the collection, taxonomic identification and preliminary extraction of the soft coral. Valter Lombardi designed and performed the anti-inflammatory experiments and related result analysis. Katja-Emilia Lillsunde, Carmen Festa, Simona De Marino, Valter Lombardi, Supriya Tilvi, Dorota A. Nawrot, Angela Zampella, Lisette D’Souza, Maria Valeria D'Auria and Päivi Tammela contributed to writing the paper.

\section{Conflicts of Interest}

The authors declare no conflict of interest.

\section{References}

1. Borgherini, G.; Poubeau, P.; Staikowsky, F.; Lory, M.; le Moullec, N.; Becquart, J.P.; Wengling, C.; Michault, A.; Paganin, F. Outbreak of Chikungunya on Reunion island: Early clinical and laboratory features in 157 adult patients. Clin. Infect. Dis. 2007, 44, 1401-1407.

2. Powers, A.M.; Logue, C.H. Changing patterns of chikungunya virus: Re-emergence of a zoonotic arbovirus. J. Gen. Virol. 2007, 88, 2363-2377.

3. Simon, F.; Parola, P.; Grandadam, M.; Fourcade, S.; Oliver, M.; Brouqui, P.; Hance, P.; Kraemer, P.; Mohamed, A.A.; de Lamballerie, X.; et al. Chikungunya Infection: An emerging rheumatism among travelers returned from Indian Ocean islands. Medicine 2007, 86, 123-137.

4. Moro, M.L.; Grilli, E.; Corvetta, A.; Silvi, G.; Angelini, R.; Mascella, F.; Miserocchi, F.; Sambo, P.; Finarelli, A.C.; Sambri, V.; et al. Long-term Chikungunya infection clinical manifestations after an outbreak in Italy: A prognostic cohort study. J. Infect. 2012, 65, 165-172.

5. Pialoux, G.; Gaüzère, B.A.; Jauréguiberry, S.; Strobel, M. Chikungunya, an epidemic arbovirosis. Lancet Infect. Dis. 2007, 7, 319-327. 
6. Gratz, N.G. Critical review of the vector status of Aedes albopictus. Med. Vet. Entomol. 2004, 18, 215-227.

7. Tsetsarkin, K.A.; Chen, R.; Leal, G.; Forrester, N.; Higgs, S.; Huang, J.; Weaver, S.C. Chikungunya virus emergence is constrained in Asia by lineage-specific adaptive landscapes. Proc. Natl. Acad. Sci. USA 2011, 108, 7872-7877.

8. Schuffenecker, I.; Iteman, I.; Michault, A.; Murri, S.; Frangeul, L.; Vaney, M.; Lavenir, R.; Pardigon, N.; Reynes, J.; Pettinelli, F.; et al. Genome microevolution of Chikungunya viruses causing the Indian Ocean outbreak. PLoS Med. 2006, 3, 1058-1070.

9. Grandadam, M.; Caro, V.; Plumet, S.; Thiberge, J.; Souarès, Y.; Failloux, A.; Tolou, H.J.; Budelot, M.; Cosserat, D.; Leparc-Goffart, I.; et al. Chikungunya virus, southeastern France. Emerg. Infect. Dis. 2011, 17, 910-913.

10. Rezza, G.; Nicoletti, L.; Angelini, R.; Romi, R.; Finarelli, A.; Panning, M.; Cordioli, P.; Fortuna, C.; Boros, S.; Magurano, F.; et al. Infection with Chikungunya virus in Italy: An outbreak in a temperate region. Lancet 2007, 370, 1840-1846.

11. Vega-Rua, A.; Zouache, K.; Caro, V.; Diancourt, L.; Delaunay, P.; Grandadam, M.; Failloux, A. High efficiency of temperate Aedes albopictus to transmit Chikungunya and Dengue viruses in the southeast of France. PLoS One 2013, 8, doi:10.1371/journal.pone.0059716.

12. Strauss, J.H.; Strauss, E.G. The alphaviruses: Gene expression, replication, and evolution. Microbiol. Rev. 1994, 58, 491-562.

13. Kaur, P.; Chu, J.J.H. Chikungunya virus: An update on antiviral development and challenges. Drug Discov. Today 2013, 18, 969-983.

14. Lakshmi, V.; Kumar, R. Metabolites from Sinularia species. Nat. Prod. Res. 2009, 23, 801-850.

15. Chao, C.H.; Hsieh, C.H.; Chen, S.P.; Lu, C.K.; Dai, C.F.; Sheu, J.H. Sinularianins A and B, novel Sesquiterpenoids from the Formosan soft coral Sinularia sp. Tetrahedron Lett. 2006, 47, 5889-5891.

16. Tseng, Y.J.; Shen, K.P.; Lin, H.L.; Huang, C.Y.; Dai, C.F.; Sheu, J.H. Lochmolins A-G, new Sesquiterpenoids from the soft coral Sinularia lochmodes. Mar. Drugs 2012, 10, 1572-1581.

17. Kamel, H.N.; Slattery, M. Terpenoids of Sinularia: Chemistry and biomedical applications. Pharm. Biol. 2005, 43, 253-269.

18. Sarma, N.S.; Krishna, M.S.; Pasha, S.G.; Rao, T.S.P.; Venkateswarlu, Y.; Parameswaran, P.S. Marine metabolites: The sterols of soft coral. Chem. Rev. 2009, 109, 2803-2828.

19. Ahmed, A.F.; Tai, S.H.; Wen, Z.H.; Su, J.H.; Wu, Y.C.; Hu, W.P.; Sheu, J.H. A C-3 Methylated isocembranoid and 10-oxocembranoids from a Formosan soft coral, Sinularia grandilobata. J. Nat. Prod. 2008, 71, 946-951.

20. Cheng, S.Y.; Chuang, C.T.; Wen, Z.H.; Wang, S.K.; Chiou, S.F.; Hsu, C.H.; Dai, C.F.; Duh, C.Y. Bioactive norditerpenoids from the soft coral Sinularia gyrosa. Bioorg. Med. Chem. 2010, 18, 3379-3386.

21. Hu, L.C.; Yen, W.H.; Su, J.H.; Chiang, M.Y.N.; Wen, Z.H.; Chen, W.F.; Lu, T.J.; Chang, Y.W.; Chen, Y.H.; Wang, W.H.; et al. Cembrane derivatives from the soft corals, Sinularia gaweli and Sinularia flexibilis. Mar. Drugs 2013, 11, 2154-2167. 
22. Lu, Y.; Huang, C.Y.; Lin, Y.F.; Wen, Z.H.; Su, J.H.; Kuo, Y.H.; Chiang, M.Y.; Sheu, J.H. Anti-inflammatory cembranoids from the soft corals Sinularia querciformis and Sinularia granosa. J. Nat. Prod. 2008, 71, 1754-1759.

23. Lu, Y.; Su, J.H.; Huang, C.Y.; Liu, Y.C.; Kuo, Y.H.; Wen, Z.H.; Hsu, C.H.; Sheu, J.H. Cembranoids from the soft corals Sinularia granosa and Sinularia querciformis. Chem. Pharm. Bull. 2010, 58, 464-466.

24. Wei, W.C.; Sung, P.J.; Duh, C.Y.; Chen, B.W.; Sheu, J.H.; Yang, N.S. Anti-inflammatory activities of natural products isolated from soft corals of Taiwan between 2008 and 2012. Mar. Drugs 2013, 11, 4083-4126.

25. Cheng, S.; Chuang, C.; Wang, S.; Wen, Z.; Chiou, S.; Hsu, C.; Dai, C.; Duh, C. Antiviral and anti-inflammatory diterpenoids from the soft coral Sinularia gyrosa. J. Nat. Prod. 2010, 73, 1184-1187.

26. Huang, K.J.; Chen, Y.C.; El-Shazly, M.; Du, Y.C.; Su, J.H.; Tsao, C.W.; Yen, W.H.; Chang, W.B.; Su, Y.D.; Yeh, Y.T.; et al. 5-Episinuleptolide Acetate, a norcembranoidal diterpene from the Formosan soft coral Sinularia sp. induces leukemia cell apoptosis through Hsp90 inhibition. Molecules 2013, 18, 2924-2933.

27. Li, G.; Zhang, Y.; Deng, Z.; van Ofwegen, L.; Proksch, P.; Lin, W. Cytotoxic cembranoid diterpenes from a soft coral Sinularia gibberosa. J. Nat. Prod. 2005, 68, 649-652.

28. Neoh, C.A.; Wang, R.Y.L.; Din, Z.H.; Su, J.H.; Chen, Y.K.; Tsai, F.J.; Weng, S.H.; Wu, Y.J. Induction of apoptosis by Sinulariolide from soft coral through mitochondrial-related and p38MAPK pathways on human bladder carcinoma cells. Mar. Drugs 2012, 10, 2893-2911.

29. Bowden, B.F.; Coll, J.C.; Mitchell, S.J.; Mulder, J.; Stokie, G.J. Studies of Australian Soft Corals. IX. A novel nor-diterpene from the soft coral Sinularia leptoclados. Aust. J. Chem. 1978, 31, 2049-2056.

30. Shoji, N.; Umeyama, A.; Arihara, S.A. Novel norditerpenoid from the Okinawan soft coral Sinularia sp. J. Nat. Prod. 1993, 56, 1651-1653.

31. Saitman, A.; Rulliere, P.; Sullivan, S.D.E.; Theodorakis, E.A. Total synthesis of Norcembrenolide B and Scabrolide D. Org. Lett. 2011, 13, 5854-5857.

32. Sheu, J.H.; Ahmed, A.F.; Shiue, R.T.; Dai, C.F.; Kuo, Y.H. Scabrolides A-D, four new norditerpenoids isolated from the soft coral Sinularia scabra. J. Nat. Prod. 2002, 65, 1904-1908.

33. Sato, A.; Fenical, W.; Qi-tai, Z.; Clardy, J. Norcembrene diterpenoids from Pacific soft-corals of the genus Sinularia (Alcyonacea; Octocorallia). Tetrahedron 1985, 41, 4303-4308.

34. Nagashima, F.; Toyota, M.; Asakawa, Y. Terpenoids from some Japanese liverworts. Phytochemistry 1990, 29, 2169-2174.

35. Duh, C.Y.; Wang, S.K.; Chia, M.C.; Chiang, M.Y. A novel cytotoxic norditerpenoid from the Formosan soft coral Sinularia inelegans. Tetrahedron Lett. 1999, 40, 6033-6035.

36. Ransohoff, R.M.; Perry, V.H. Microglial physiology: Unique stimuli, specialized responses. Annu. Rev. Immunol. 2009, 27, 119-145.

37. Glass, C.K.; Saijo, K.; Winner, B.; Marchetto, M.C.; Gage, F.H. Mechanisms underlying inflammation in neurodegeneration. Cell 2010, 140, 918-934.

38. Perry, V.H.; Nicoll, J.A.R.; Holmes, C. Microglia in neurodegenerative disease. Nat. Rev. Neurol. 2010, 6, 193-201. 
39. Kubanek, J.; Jensen, P.R.; Keifer, P.A.; Sullards, M.C.; Collins, D.O.; Fenical, W. Seaweed resistance to microbial attack: A targeted chemical defense against marine fungi. Proc. Natl. Acad. Sci. USA 2003, 100, 6916-6921.

40. Radhika, P.; Subba Rao, P.V.; Anjaneyulu, V.; Asolkar, R.N.; Laatsch, H. Horiolide, a novel norditerpenoid from Indian Ocean soft coral of the Genus Sinularia. J. Nat. Prod. 2002, 65, 737-739.

41. Li, Y.; Pattenden, G. Novel macrocyclic and polycyclic norcembranoid diterpenes from Sinularia. species of soft coral: Structural relationships and biosynthetic speculations. Nat. Prod. Rep. 2011, 28, 429-440.

42. Li, Y.; Pattenden, G. Biomimetic syntheses of ineleganolide and sinulochmodin C from 5-episinuleptolide via sequences of transannular Michael reactions. Tetrahedron 2011, 67, 10045-10052

43. Parhamifar, L.; Wu, L.; Andersen, H.; Moghimi, S.M. Live-cell fluorescent microscopy platforms for real-time monitoring of polyplex-cell interaction: Basic guidelines. Methods 2014, 68, 300-307.

44. Liang, C.H.; Wang, G.H.; Chou, T.H.; Wang, S.H.; Lin, R.J.; Chan, L.P.; So, E.C.; Sheu, J.H. 5-epi-Sinuleptolide induces cell cycle arrest and apoptosis through tumor necrosis factor/mitochondria-mediated Caspase signaling pathway in human skin cancer cells. BBA Gen. Subj. 2012, 1820, 1149-1157.

45. Yen, W.; Hu, L.; Su, J.; Lu, M.; Twan, W.; Yang, S.; Kuo, Y.; Weng, C.; Lee, C.; Kuo, Y.; et al. Norcembranoidal diterpenes from a Formosan soft coral Sinularia sp. Molecules 2012, 17, 14058-14066.

46. Ledeboer, A.; Brevé, J.J.P.; Poole, S.; Tilders, F.J.H.; van Dam, A. Interleukin-10, interleukin-4, and transforming growth factor-beta differentially regulate lipopolysaccharide-induced production of pro-inflammatory cytokines and nitric oxide in co-cultures of rat astroglial and microglial cells. Glia 2000, 30, 134-142.

47. Molina-Holgado, F.; Grencis, R.; Rothwell, N.J. Actions of exogenous and endogenous IL-10 on glial responses to bacterial LPS/Cytokines. Glia 2001, 33, 97-106.

48. Takaki, H.; Koganemaru, R.; Iwakawa, Y.; Higuchi, R.; Miyamoto, T. Inhibitory effect of norditerpenes on LPS-induced TNF-alpha; Production from the Okinawan soft coral, Sinularia sp. Biol. Pharm. Bull. 2003, 26, 380-382.

49. Avonto, C.; Taglialatela-Scafati, O.; Pollastro, F.; Minassi, A.; di-Marzo, V.; de-Petrocellis, L.; Appendino, G. An NMR spectroscopic method to identify and classify thiol-trapping agents: Revival of Michael acceptors for drug discovery? Angew. Chem. Int. Ed. 2011, 50, 467-471.

50. Powers, J.C.; Asgian, J.L.; Ekici, O.D.; James, K.E. Irreversible inhibitors of Serine, Cysteine, and Threonine proteases. Chem. Rev. 2002, 102, 4639-4750.

51. Amslinger, S. The tunable functionality of $\alpha, \beta$-unsaturated carbonyl compounds enables their differential application in biological systems. Chem. Med. Chem. 2010, 5, 351-356.

52. Pohjala, L.; Utt, A.; Varjak, M.; Lulla, A.; Merits, A.; Ahola, T.; Tammela, P. Inhibitors of alphavirus entry and replication identified with a stable Chikungunya replicon cell line and virus-based assays. PLoS One 2011, doi:10.1371/journal.pone.0028923. 
53. Bollini, S.; Herbst, J.J.; Gaughan, G.T.; Verdoorn, T.A.; Ditta, J.; Dubowchik, G.M.; Vinitsky, A. High-throughput fluorescence polarization method for identification of FKBP12 ligands. J. Biomol. Screen. 2002, 7, 526-530.

54. Takata, K.; Kitamura, Y.; Tsuchiya, D.; Kawasaki, T.; Taniguchi, T.; Shimohama, S. High mobility group Box Protein-1 inhibits microglial $A \beta$ clearance and enhances $A \beta$ neurotoxicity. J. Neurosci. Res. 2004, 78, 880-891.

55. Choi, D.K.; Koppula, S.; Suk, K. Inhibitors of microglial neurotoxicity: Focus on natural products. Molecules 2011, 16, 1021-1043.

(C) 2014 by the authors; licensee MDPI, Basel, Switzerland. This article is an open access article distributed under the terms and conditions of the Creative Commons Attribution license (http://creativecommons.org/licenses/by/3.0/). 